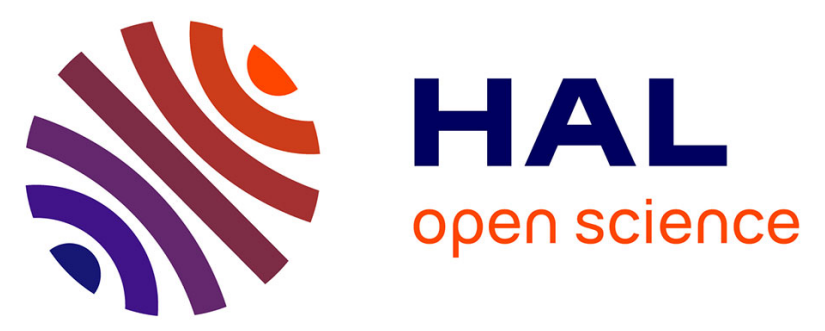

\title{
A Step Forward in Understanding the Hydrogen Adsorption and Compression on Activated Carbons
}

Pamela Ramirez-Vidal, Rafael L S Canevesi, Giuseppe Sdanghi, Sébastien Schaefer, Gaël Maranzana, Alain Celzard, Vanessa Fierro

\section{- To cite this version:}

Pamela Ramirez-Vidal, Rafael L S Canevesi, Giuseppe Sdanghi, Sébastien Schaefer, Gaël Maranzana, et al.. A Step Forward in Understanding the Hydrogen Adsorption and Compression on Activated Carbons. ACS Applied Materials \& Interfaces, 2021, 13 (10), pp.12562-12574. 10.1021/acsami.0c22192 . hal-03161863

\section{HAL Id: hal-03161863 \\ https://hal.univ-lorraine.fr/hal-03161863}

Submitted on 8 Mar 2021

HAL is a multi-disciplinary open access archive for the deposit and dissemination of scientific research documents, whether they are published or not. The documents may come from teaching and research institutions in France or abroad, or from public or private research centers.
L'archive ouverte pluridisciplinaire HAL, est destinée au dépôt et à la diffusion de documents scientifiques de niveau recherche, publiés ou non, émanant des établissements d'enseignement et de recherche français ou étrangers, des laboratoires publics ou privés. 


\title{
A step forward in understanding the hydrogen adsorption and compression on activated carbons
}

\author{
Pamela Ramirez-Vidal ${ }^{1}$, Rafael L. S. Canevesi ${ }^{1}$, Giuseppe \\ Sdanghi $^{1,2}$, Sébastien Schaefer ${ }^{1}$, Gaël Maranzana ${ }^{2}$, Alain Celzard ${ }^{1}$, \\ Vanessa Fierro ${ }^{1} *$
}

1 Université de Lorraine, CNRS, IJL, F-88000 Epinal, France

2 Université de Lorraine, CNRS, LEMTA, F-54000 Nancy, France

* Corresponding author. Tel: + 33372749677.

Fax: + 33372749638 .

E-mail address : Vanessa.Fierro@univ-lorraine.fr (V. Fierro) 


\begin{abstract}
Hydrogen adsorption on activated carbons (ACs) is a promising alternative to compression and liquefaction for storing hydrogen. Herein, we have studied hydrogen adsorption on six commercial ACs (CACs) with surface areas ranging from 996 to $2216 \mathrm{~m}^{2} \mathrm{~g}^{-1}$, in a temperature range of 77 to $273 \mathrm{~K}$ and pressures up to $15 \mathrm{MPa}$. Excess hydrogen adsorption capacities of 2.3 to 5.8 wt. $\%$ were obtained at $77 \mathrm{~K}$ and $4 \mathrm{MPa}$. We demonstrated that, contrary to what is normally done, hydrogen capacity is more accurately predicted by the surface area determined by the NLDFT method applied to $\mathrm{N}_{2}$ and $\mathrm{CO}_{2}$ adsorption data, than by the BET area. The modified Dubinin-Astakhov (MDA) equation was used to fit the experimental adsorption data, and the relationship between the MDA parameters $\left(n_{\max }, V_{a}, \alpha\right.$ and $\left.\beta\right)$ and the textural properties of the CACs was brought for the first time. We concluded that the $n_{\max }$ and $V_{a}$ parameters are related to the BET area while the $\alpha$ and $\beta$ parameters are related to average micropore size and total pore volume, respectively. $\alpha$ and $\beta$ were used to evaluate the enthalpy and entropy of adsorption and we show that these parameters can be used to assess the best carbon for hydrogen storage or compression.
\end{abstract}

Keywords: hydrogen storage; activated carbons; adsorption modelling; high-pressure adsorption; isosteric heat; adsorption entropy. 


\section{Introduction}

Hydrogen is an attractive energy vector to replace fossil fuels because it has the highest gravimetric energy density among all non-nuclear fuels (i.e., $120 \mathrm{MJ} \mathrm{kg}^{-1}$ compared to oil, 47 $\mathrm{MJ} \mathrm{kg}^{-1}$ ). However, hydrogen is also the lightest element in the universe. Therefore, several technological challenges need to be overcome in order to plan its large-scale implementation, such as environmentally friendly production and efficient distribution, storage and use ${ }^{1-4}$. In order to meet the storage targets to power a fuel cell vehicle and cover a distance of $500 \mathrm{~km}, 5$ $\mathrm{kg}$ of hydrogen should be stored at $298 \mathrm{~K}$ and $0.1 \mathrm{MPa},{ }^{3}$ for a total storage volume of $61 \mathrm{~m}^{3}$. To solve this problem, three approaches have been considered: (i) compression in gas cylinders ${ }^{4-6}$; (ii) liquefaction in cryogenic tanks ${ }^{7,8}$ and; (iii) absorption or adsorption in solids (metal hydrides ${ }^{9}$, metallic organic frameworks ${ }^{10,11}$, nanostructured carbons ${ }^{12-14}$, hypercrosslinked polymers ${ }^{15}$ ).

Compression is the most widely used method for hydrogen storage ${ }^{4}$, although very high pressures have to be used to achieve a significant increase in hydrogen density. Indeed, a density of $42.9 \mathrm{~g} \mathrm{~L}^{-1}$ is obtained by compressing hydrogen to $70 \mathrm{MPa}$ and $298 \mathrm{~K}$, which results in a four order of magnitude increase in density compared to ambient conditions. Highpressure hydrogen storage requires heavy and bulky tanks. Type IV tanks, which are made of carbon fibers and a polymer inner lining, are the most commonly used for storing hydrogen at high pressure ${ }^{16}$. The cost of a Type IV tank has been estimated at approximately $\$ 633 \mathrm{~kg}^{-16}$. Nevertheless, high-pressure systems require safety measures that may alarm public opinion. Another proposed approach for storing hydrogen is its liquefaction in cryogenic tanks. The estimated cost of a liquid hydrogen tank is $\$ 386 \mathrm{~kg}^{-1}$ for a $100 \mathrm{~L}$ internal volume reservoir for automotive applications ${ }^{8}$. In addition, it should be considered that the most modern hydrogen 
liquefaction plants have a specific energy demand of approximately $10 \mathrm{kWh} \mathrm{kg}^{-1}{ }^{17}$, a third of the energy contained in hydrogen.

Having a similar expected cost that the liquefaction of hydrogen in cryogenic tanks $(390$ \$ $\left.\mathrm{kg}^{-1}\right)^{8}$, the cryo-compression is a viable alternative for storing hydrogen. In fact, cryocompression needs less strength materials compared to a 70MPa room compression and can overcome the gas lost associated to the boil-off in the $\mathrm{H}_{2}$ liquefaction systems ${ }^{18,19}$. The volume of the hydrogen storage system can be significantly reduced by introducing a porous material to promote hydrogen adsorption. Indeed, it has been observed that the use of activated carbons (ACs) can reduce the volume needed for hydrogen storage by $23 \%$ compared to pure compression at $20 \mathrm{MPa}$ and room temperature ${ }^{20,21}$. Hydrogen storage in ACs is achieved by physisorption, which is a physical phenomenon since no chemical bonding between the hydrogen molecules and the carbon surface is involved. It is widely known that hydrogen interacts with the carbon surface through charge density fluctuations, i.e., van der Waals interactions ${ }^{14,22}$. ACs have, on average, the highest hydrogen adsorption capacities among currently known nanotextured carbon materials (up to 7 wt. \% at $4 \mathrm{MPa}$ and $77 \mathrm{~K})^{14,24}$.

The amount of hydrogen that can be physisorbed on a porous material, at a given pressure and temperature, depends essentially on its textural properties. Hydrogen storage is enhanced in materials with an adequate micropore size distribution and high surface area. Furthermore, hydrogen adsorption on ACs is thermodynamically favored at low temperature and high pressure because it is an exothermic process. Thus, hydrogen uptake at $77 \mathrm{~K}$ is assumed to increase by 1 wt. \% per $500 \mathrm{~m}^{2} \mathrm{~g}^{-1}$ of BET area, a behavior known as "Chahine's rule" ${ }^{25}$.

In the framework of hydrogen adsorption modeling, the Ono-Kondo theory proved to be in very good agreement with hydrogen adsorption isotherms measured up to $6 \mathrm{MPa}$ and over a 
wide temperature range $(77-298 \mathrm{~K})^{26}$. The modeling of hydrogen adsorption isotherms with the Sips equation, also called Langmuir-Freundlich isotherm, also gave very good predictions 27, although the Toth equation proved to be better adapted than the Sips equation at low pressure ${ }^{28}$. The modified Dubinin-Astakhov (MDA) equation also proved to fit accurately $\mathrm{N}_{2}$, $\mathrm{CH}_{4}$ and $\mathrm{H}_{2}$ adsorption isotherms on $\mathrm{ACs}{ }^{29,30}$. However, the physical significance of the MDA parameters is not completely understood and is of primary importance for the design of hydrogen storage systems.

In our previous study ${ }^{31}$, we determined hydrogen adsorption on two commercial ACs, MSC30 and MSP20X from Kansai Coke and Chemicals ${ }^{\mathrm{TM}}$ (Japan), and used the MDA equation to fit the experimental hydrogen adsorption over a wide range of pressures and temperatures. We found that the parameters of the MDA model were related in some way to the textural properties of the ACs used. However, as the panel of ACs was reduced to only two, we could not draw indisputable conclusions. The MDA equation was also used to evaluate the heat of adsorption as an alternative to other well-known methods, such as isosteric sorption and calorimetric-volumetric methods ${ }^{32,33}$. As the heat of adsorption can significantly affect the hydrogen storage capacity of ACs, the usable hydrogen uptake in an adsorption system can be enhanced when the heat of adsorption is effectively removed from the system ${ }^{34}$. A good knowledge of the variation of the heat of adsorption with the textural properties of the $\mathrm{AC}$ is therefore essential to design an appropriate thermal management of a hydrogen storage system.

In this study, we used six ACs with very different textural characteristics to better understand hydrogen adsorption on ACs and to elucidate the dependence of the MDA parameters. We have shown that four out of the five parameters of the MDA equation are correlated ( $\mathrm{R}^{2}$ between 0.95 and 0.99$)$ to the textural properties of the CACs. 


\section{Experimental}

\subsection{Carbon materials}

Six commercial activated carbons (CACs) were studied, namely: MAXSORB® (i) MSC30 and (ii) MSP20X from Kansai Coke and Chemicals ${ }^{\mathrm{TM}}$ (Japan); (iii) SA1500 and (iv) SA20 from Nunchar Ingevity® (USA); (v) TH90I from Silcarbon ${ }^{\circledR}$ (Germany) and (vi) Filtrasorb400 from Chemviron® (Belgium).

\subsection{Textural characterization}

Textural characterization of the samples was determined by adsorption of $\mathrm{N}_{2}(77 \mathrm{~K})$ and $\mathrm{CO}_{2}(273 \mathrm{~K})$ in two automatic adsorption apparatus from Micromeritics-Particulate Systems®, ASAP 2020 and ASAP 2040, respectively. Outgassing was carried out at 383K under secondary vacuum for more than $48 \mathrm{~h}$, before sample weight determination, and further outgassing was carried out at the measuring port at $383 \mathrm{~K}$ and under secondary vacuum for at least $6 \mathrm{~h}$. More details are given elsewhere ${ }^{12,35}$. Data treatment of the adsorption isotherms was performed with the Microactive software ${ }^{\circledR}$ provided by Micromeritics. We calculated the BET areas, $A_{B E T}$, in the adequate range of relative pressures of the $\mathrm{N}_{2}$ adsorption data (see Table S1 of the Supporting Information), taking into consideration the Rouquerol criterion $^{23,36}$. Micropore volumes were obtained by applying the Dubinin-Radushkevich (DR) equation to either $\mathrm{N}_{2}, V_{\mu, D R-N 2}$, or $\mathrm{CO}_{2}, V_{\mu}$ DR-CO2, adsorption data. For the determination of the pore size distributions (PSDs), the SAIEUS ${ }^{\circledR}$ software provided by Micromeritics was used ${ }^{37}$. Combining $\mathrm{N}_{2}$ and $\mathrm{CO}_{2}$ sorption data by the non-local density functional theory (NLDFT), we obtained the surface areas, $S_{N L D F T}$, and the pore size distributions (PSDs). For that purpose, we applied the two-dimensional version of the heterogeneous carbon surface model, 2D-NLDFT-HS ${ }^{38}$, to the $\mathrm{N}_{2}$ and $\mathrm{CO}_{2}$ adsorption data in the entire range of relative 
pressures. By integration of the PSDs, we obtained the total pore volumes, $V_{T}$, and the volumes of pores having diameters: (i) under $0.7 \mathrm{~nm}\left(V_{<0.7, \mathrm{NLDFT}}\right)$, i.e., ultramicropores; (ii) between 0.7 and $2 \mathrm{~nm}\left(V_{0.7-2, \mathrm{NLDFT}}\right)$, i.e., supermicropores; (iii) under $2 \mathrm{~nm}\left(V_{\text {micro }}\right)$, i.e., micropores; and (iv) between 2 and $50 \mathrm{~nm}\left(V_{\text {mes }}\right)$, i.e., mesopores, calculated as $V_{T^{-}} V_{\text {micro }}$. Micropore $\left(\bar{d}_{\mu}\right)$ and total $\left(\bar{d}_{T}\right)$ average pore sizes were calculated taking into account the PSDs and were volume-weighted.

2.3 Determination of hydrogen adsorption isotherms

The determination of the hydrogen adsorption isotherms was carried out in an automatic adsorption equipment HPVAII from Micromeritics-Particulate Systems ${ }^{\circledR}$ coupled with a single-stage closed cycle cryogenic refrigerator. Before hydrogen adsorption at high pressure, the AC was outgassed first in a vacuum oven at $373 \mathrm{~K}$ overnight under primary vacuum. Then, the AC was transferred to the high-pressure device: a $10 \mathrm{~cm}^{3}$ cell was filled with about $1.2 \mathrm{~g}$ of AC and submitted to further outgassing at $373 \mathrm{~K}$ for $48 \mathrm{~h}$ under secondary vacuum.

Measurements were performed in a range of temperatures from 77 to $273 \mathrm{~K}$ with an accurate temperature control (margin of error $\pm 0.005 \mathrm{~K}$ ). We fixed the pressure steps for hydrogen adsorption at $0.1,0.5,0.8,1,2,3,5,7.5,10,12.5$ and $14 \mathrm{MPa}$, whereas we took desorption data at $11.5,8,4.5,1.5$ and $0.5 \mathrm{MPa}$. Outgassing between adsorption and desorption experiments was carried out overnight under secondary vacuum at room temperature. The first isotherm was repeated twice to confirm the good repeatability of the results.

In addition, the determination of high-resolution hydrogen isotherms at $77 \mathrm{~K}$ and up to 0.1 MPa was carried out in a 3-Flex automatic device (Micromeritics) after outgassing the sample at $383 \mathrm{~K}$ for at least $24 \mathrm{~h}$. Further outgassing of the samples was carried out in the analysis 
ports for at least $8 \mathrm{~h}$. The measurement of the cold and warm volumes was performed after the adsorption-desorption experiments to avoid helium entrapment in narrow pores.

\section{Modeling}

\subsection{Application of the MDA equation}

Hydrogen storage capacities can be measured by both gravimetric and volumetric devices. Gravimetric devices provide values of absolute hydrogen adsorption, which is defined as the amount of gas confined in a volume that has a higher concentration than the bulk free gas. The volume associated with absolute adsorption is defined by that of the adsorbed layer, a non-empirical parameter ${ }^{39}$. Volumetric devices provide values of excess hydrogen adsorption, $n_{e x c}$, defined as the difference between the hydrogen uptake on the surface of the adsorbent at a specific temperature and pressure, and the amount that would be present in the same volume and under the same conditions in the absence of adsorption forces. $n_{\text {exc }}\left[\mathrm{mol} \mathrm{kg}^{-}\right.$ ${ }^{1}$ ] on ACs can be properly represented by the MDA equation ${ }^{29,30,40-43}$, which reads as follows:

$$
n_{\text {exc }}=n_{\text {max }} \exp \left[-\left(\frac{R T}{\alpha+T \beta}\right)^{2} \ln ^{2}\left(\frac{P_{0}}{P}\right)\right]-\rho_{g} V_{a}
$$

where $n_{\max }\left[\mathrm{mol} \mathrm{kg}{ }^{-1}\right]$ is the amount of adsorbed hydrogen corresponding to the saturation of the entire available pore volume, $R\left[8.314 \mathrm{~J} \mathrm{~mol}^{-1} \mathrm{~K}^{-1}\right]$ is the universal gas constant, $\alpha\left[\mathrm{J} \mathrm{mol}^{-}\right.$ $\left.{ }^{1}\right]$ is the "enthalpy" factor, $\beta\left[\mathrm{mol} \mathrm{J}^{-1} \mathrm{~K}^{-1}\right]$ is the "entropy" factor ${ }^{30}, P_{0}[\mathrm{MPa}]$ is the pseudosaturation pressure according to Dubinin's definition ${ }^{44}, \rho_{g}\left[\mathrm{~mol} \mathrm{~m}^{-3}\right]$ is the hydrogen bulk phase density and $V_{a}\left[\mathrm{~m}^{3} \mathrm{~kg}^{-1}\right]$ is the volume of the adsorbed phase. As far as we know, only one study considered the variation of $V_{a}$ with the temperature and the amount adsorbed ${ }^{45} . V_{a}$ is usually considered as constant under supercritical conditions by several authors ${ }^{29,46,47}$. We also consider that the adsorbed phase occupies the available porosity and that its average density increases gradually to an asymptotic value during hydrogen adsorption ${ }^{29}$. 
For the determination of the absolute amount of hydrogen adsorbed, $n_{a b s}\left[\mathrm{~mol} \mathrm{~kg}^{-1}\right]$, we used the following expression:

$$
n_{a b s}=n_{e x c}+\rho_{g} V_{a}
$$

The adsorption data obtained for each CAC at the nine temperatures chosen in this study were fitted simultaneously. This solution allowed obtaining a set of only five parameters $\left(n_{\max }, \alpha, \beta, P 0\right.$ and $\mathrm{Va}$ ) valid for the entire temperature range considered and for a given CAC. $\rho g$ was calculated by using the REFPROP-7 software.

The Levenberg-Marquardt algorithm ${ }^{48}$ was used to solve the non-linear fitting of the curves and get the MDA parameters for each AC. Then, we established the relationships between the MDA parameters and the textural properties of the ACs.

3.2 Determination of the isosteric heats of adsorption

The isosteric heat of adsorption, $Q_{s t}\left[\mathrm{~kJ} \mathrm{~mol}^{-1}\right]$, can be deduced from the MDA equation using the following expression:

$$
Q_{s t}^{M D A}=-\Delta H_{a d s}=\alpha \sqrt{-\ln \left(\frac{n_{a b s}}{n_{\max }}\right)}
$$

where $n_{a b s} / n_{\text {max }}$ is the fractional filling on the surface of the AC, usually referred to as $\Theta$.

$Q_{s t}$ was also calculated by the Clausius-Clapeyron equation as follows:

$$
Q_{s t}=-R\left[\frac{\partial \ln P}{\partial\left(\frac{1}{T}\right)}\right]_{n_{a}, V}
$$

The Clausius-Clapeyron equation was applied to groups of three adsorption isotherms in order to get $Q_{s t}$ as a function of both temperature and absolute amount of hydrogen adsorbed. In order to calculate the $Q_{s t}$ of the six CACs by the classical Clausius-Clapeyron equation, we 
applied the Sips equation, which is the most appropriate for studying the thermodynamics of hydrogen adsorption ${ }^{27}$, to calculate the absolute adsorbed amounts $\left(n_{a b s}\right)$ in the equilibrium pressure range of the study. According to the Sips equation, $n_{a b s}$ is calculated as follows:

$$
n_{a b s}=N \frac{b P^{k}}{1+b P^{k}}
$$

where $N$ is the maximum adsorption capacity of the material at a given temperature, $b$ is the equilibrium constant related to the Langmuir adsorption coefficient and $k$ is the coefficient related to the Freundlich equation. When $P$ or $b$ approaches 0 , the Sips expression reduces to that of Freundlich, whereas if $k$ is equal to 1, Eq. (5) becomes the Langmuir equation ${ }^{49}$. The hydrogen absolute isotherms were calculated from the excess isotherms by means of Eq. (2). $V_{a}$ was estimated for each temperature assuming asymptotic behavior at high fugacity values.

The specific pressures, $P$, to apply the Clausius-Clapeyron equation were calculated by Eq. (6):

$$
P=\left[\frac{n_{a b s}}{b\left(N-n_{a b s}\right)}\right]^{\frac{1}{k}}
$$

In the present study, fugacity was used instead of pressure because of the deviation from ideal conditions, and was calculated as a function of temperature and pressure using the REFPROP7 software. In this way, Eq. (4) can be expressed as a function of fugacity according to:

$$
-\frac{Q_{s t}}{R}=\frac{\partial \ln (f)}{\partial(1 / T)}
$$

\subsection{Determination of adsorption entropies}

The entropy of the adsorbed hydrogen with respect to the entropy of the perfect gas phase at $0.1 \mathrm{MPa}$ and the same temperature, $\Delta S_{a d s}^{M D A}\left[\mathrm{~J} \mathrm{~kg}^{-1} \mathrm{~K}^{-1}\right]$, can be calculated from the MDA equation $^{30}$ : 


$$
\begin{aligned}
\Delta S_{a d s}^{M D A}=S_{a}- & n_{a} s_{g}{ }^{0}= \\
= & \frac{n_{\max } \beta \sqrt{\pi}}{2}\left[1-\operatorname{Erf}\left(\sqrt{-\ln \left(\frac{n_{a b s}}{n_{\max }}\right)}\right)\right]+n_{a b s}\left[\beta \sqrt{-\ln \left(\frac{n_{a b s}}{n_{\max }}\right)}\right] \\
& +n_{a b s} R \ln \left(\frac{P^{0}}{P_{0}}\right)
\end{aligned}
$$

where $s_{g}{ }^{0}$ is the entropy of the perfect gas phase at $0.1 \mathrm{MPa}$ and at the same temperature as the adsorbed phase, Erf is the error function and $P^{0}$ is the pressure of the reference state, i.e., 0.1 MPa.

According to the second law of thermodynamics, and once the adsorption equilibrium is reached, the variation of entropy due to hydrogen adsorption, $\Delta S_{a d s}\left[\mathrm{~J} \mathrm{~mol}^{-1} \mathrm{~K}^{-1}\right]$, can be related to $Q_{s t}$ as follows:

$$
\Delta S_{a d s}=\frac{\Delta H_{a d s}}{T}=\frac{-Q_{s t}}{T}
$$

$\Delta S_{a d s}$ was calculated from $-Q_{s t}$ (Eq. (7)), and correspond to a given filling; it is therefore not directly comparable to $\Delta S_{a d s}^{M D A}$ calculated by Eq. (8) because the latter corresponds to the total hydrogen adsorbed and refers to the amount of carbon and not to the amount of hydrogen adsorbed.

\section{Results and discussion}

\subsection{Textural characterization}

Figures $1 \mathrm{a}$ and $1 \mathrm{~b}$ show the $\mathrm{N}_{2}$ and $\mathrm{CO}_{2}$ isotherms of the CACs studied, respectively. We determined their PSDs by applying the 2D-NLDFT-HS model to both adsorption isotherms simultaneously. This approach gives a more accurate view of the textural properties of the selected ACs, and especially of the narrowest pores. Although the kinetic diameters of $\mathrm{N}_{2}$ and 
$\mathrm{CO}_{2}$ are quite similar (3.6 and $3.3 \mathrm{~nm}$, respectively), $\mathrm{CO}_{2}$ physisorption at $273 \mathrm{~K}$ is a much faster process than that of $\mathrm{N}_{2}$ at $77 \mathrm{~K}$ because molecular diffusion is highly temperaturedependent ${ }^{50,51} \cdot \mathrm{CO}_{2}$ adsorption isotherms give a reliable indication of porosity with a diameter of less than $1 \mathrm{~nm}$ because $\mathrm{CO}_{2}$ is adsorbed in pores where $\mathrm{N}_{2}$ cannot enter, within the set equilibrium times ${ }^{50,52}$.

The six investigated CACs presented very different textural properties, with $A_{B E T}$ ranging from 983 to $3310 \mathrm{~m}^{2} \mathrm{~g}^{-1}$. A high percentage of mesoporous volume was observed for MSC30 (40\%), SA1500 (50\%) and SA20 (59\%), while MSP20X, TH90I and Filtrasorb400 were essentially microporous with fractions of micropores of 94, 94 and $80 \%$, respectively. The volume of pores narrower than $1 \mathrm{~nm}$, given by $\mathrm{CO}_{2}$ isotherms (Figure $1 \mathrm{~b}$ ), decreased in the order TH90 > MSC30 $\approx$ MSP20X > SA1500 > Filtrasorb400 > SA20.

According to the IUPAC classification ${ }^{23}$, the $\mathrm{N}_{2}$ isotherm measured for MSC-30 has a type Ib shape without hysteresis loop (see Figure 1a), which is characteristic of ACs with a large fraction of supermicropores and narrow mesopores. MSC-30 exhibited more developed textural properties than all the ACs selected for this study: $A_{B E T}=3310 \mathrm{~m}^{2} \mathrm{~g}^{-1}, S_{N L D F T}=2216$ $\mathrm{m}^{2} \mathrm{~g}^{-1}$ and $V_{T}=1.60 \mathrm{~cm}^{3} \mathrm{~g}^{-1}$ (Figure 1d). An important difference is observed when comparing $A_{B E T}$ and $S_{N L D F T}$ values. The BET method is indeed known to underestimate the surface area when ultramicropores, i.e., with a pore diameter less than $0.7 \mathrm{~nm}$, exist. This is because a single monolayer of $\mathrm{N}_{2}$ is adsorbed in very narrow pores, while the presence of two pore walls should be taken into account to give a more realistic value of the surface area. In addition, the BET method also overestimates the surface area in ACs having a large fraction of supermicropores, since $\mathrm{N}_{2}$ uptake proceeds by pore filling ${ }^{53}$. For these reasons, reported $A_{B E T}$ values are sometimes higher than $3000 \mathrm{~m}^{2} \mathrm{~g}^{-1}$, although it is well known that the specific surface area of an AC should be always smaller than the theoretical surface area of a graphene sheet, i.e., $2630 \mathrm{~m}^{2} \mathrm{~g}^{-154,55}$. 
Samples SA1500 and SA20 showed a combination of type Ib and type IVa isotherms with an $\mathrm{H} 4$ hysteresis loop in the $P / P_{0}$ range of $0.4-0.8$, indicating the presence of both micropores and mesopores (50 and 59\%, respectively). They both had relatively high $A_{B E T}$, equal to 2204 and $1737 \mathrm{~m}^{2} \mathrm{~g}^{-1}$, and $S_{N L F T}$ equal to 1621 and $1305 \mathrm{~m}^{2} \mathrm{~g}^{-1}$, respectively. Filtrasorb400, TH90I and MSP20X presented $\mathrm{N}_{2}$ isotherms type Ia without hysteresis loop, which are characteristic of microporous materials with narrow porosity. MSP20X presented the largest surface area of the aforementioned samples $\left(A_{B E T}=2363 \mathrm{~m}^{2} \mathrm{~g}^{-1}\right.$ and $\left.S_{N L D F T}=2007 \mathrm{~m}^{2} \mathrm{~g}^{-1}\right)$, followed by TH90I $\left(A_{B E T}=1204 \mathrm{~m}^{2} \mathrm{~g}^{-1}\right.$ and $\left.S_{N L D F T}=1256 \mathrm{~m}^{2} \mathrm{~g}^{-1}\right)$ and Filtrasorb400 $\left(A_{B E T}=983 \mathrm{~m}^{2} \mathrm{~g}^{-1}\right.$ and $\left.S_{N L D F T}=996 \mathrm{~m}^{2} \mathrm{~g}^{-1}\right)$. MSP20X and TH90I had a higher percentage of micropores $(94 \%)$ than FiltraSorb400 (80\%). The higher surface area of MSP20X is due to supermicropores (0.7-2 nm), which produce the widening of the isotherm elbow. 

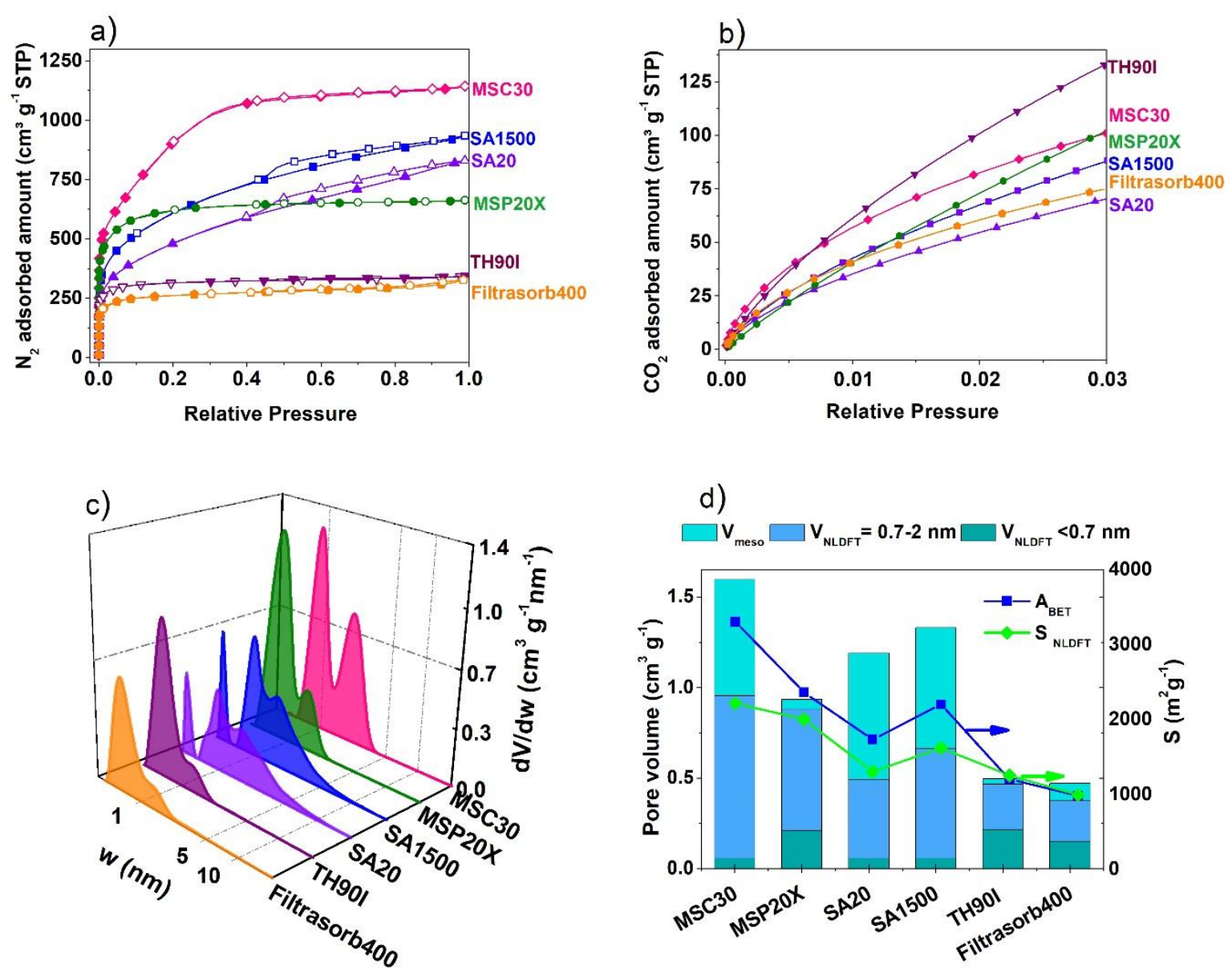

d)

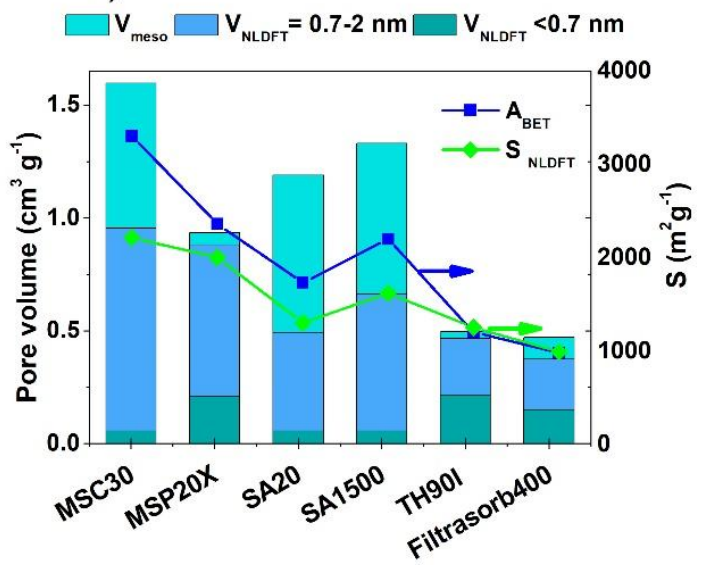

Figure 1. Textural characteristics of the CACs: (a) $\mathrm{N}_{2}$ adsorption-desorption isotherms at $77 \mathrm{~K}$; (b) $\mathrm{CO}_{2}$ adsorption isotherms at $273 \mathrm{~K}$; (c) Pore size distributions; (d) $A_{B E T}$, $S_{N L D F T}$ and pore volumes in the ultramicropore $(<0.7 \mathrm{~nm})$, supermicropore $(0.7-2$ $\mathrm{nm})$ and mesopore $(2-50 \mathrm{~nm})$ ranges.

Figure 1c shows the PSDs of all the CACs studied and Figure 1d shows their pore volumes corresponding to the ultramicropore, supermicropore and mesopore ranges. Figure $1 \mathrm{~d}$ also shows the $A_{B E T}$ and $S_{N L D F T}$. As expected, the specific surface area is proportional to the micropore volume. Full details on the textural properties of the six CACs studied are reported in the Supporting Information, Table S1. The CACs with a high percentage of mesopores i.e., MSC30X, SA1500 and SA20, presented average micropore sizes of 1.28, 1.27 and $1.26 \mathrm{~nm}$ (in the supermicropore range) and average pore sizes of 1.95, 3.21 and $3.80 \mathrm{~nm}$ (near or in the 
mesopore range), respectively. On the other hand, the microporous CACs had narrower average micropore sizes: $1.05,0.87$ and $0.92 \mathrm{~nm}$ for MSP20X, TH90I and Filtrasorb400, respectively.

\subsection{Hydrogen adsorption}

Hydrogen adsorption on all six CACs was found to be completely reversible. The desorption isotherms overlapped those of adsorption without any hysteresis loop throughout the 0.1 to $15 \mathrm{MPa}$ pressure range. Figure 2 shows the hydrogen adsorption-desorption isotherms at the lowest temperature, i.e., $77 \mathrm{~K}$ (Figure $2 \mathrm{a}$ ) and at the highest one, i.e., $273 \mathrm{~K}$ (Figure 2b), for all materials.
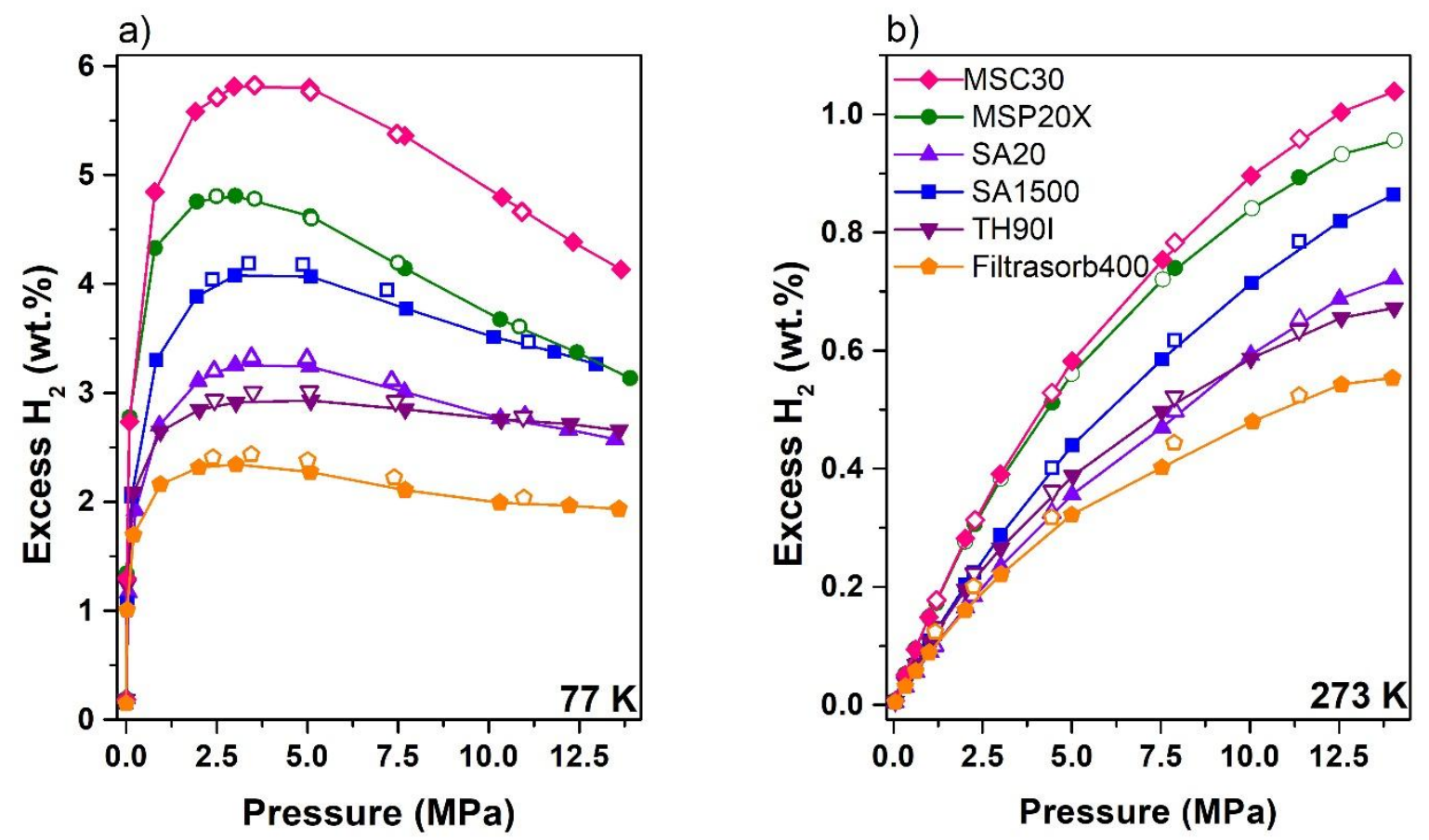

Figure 2. Excess hydrogen isotherms: (a) at $77 \mathrm{~K}$; and (b) at $273 \mathrm{~K}$, for the 6 CACs. Filled and empty symbols correspond to adsorption and desorption data, respectively, and the legend in (b) also applies to (a). 
A maximum of excess hydrogen adsorption was observed at $77 \mathrm{~K}$ and 3-4 MPa, due to the increased density of the adsorbed phase as the temperatures were lowered ${ }^{49}$. Although this maximum is reached at lower pressures when increasing the fraction of narrower pores ${ }^{75}$, Filtrasorb400 has the highest fraction of narrow pores and reached a maximum hydrogen uptake of 2.34 wt. \% at $3 \mathrm{MPa}$. For his reason, we have chosen to report hydrogen capacities at 4MPa for all the CACs except for Filtrasorb400. This value was 5.78, 4.74, 4.04, 3.24, 2.90 and 2.31 wt. $\%$ for MSC30, MSP20X, SA1500, SA20, TH90I and Filtrasorb400, respectively. Figure $2 \mathrm{~b}$ shows that the excess hydrogen adsorption increases steadily with pressure at 273 $\mathrm{K}$; the values obtained at $14 \mathrm{MPa}$ were $1.04,0.95,0.86,0.72,0.67$ and 0.55 wt. \% for the same carbons and in the same order of adsorption capacity as mentioned for the adsorption data at $77 \mathrm{~K}$ (Figure 2a).

Figure 3 shows the 3D plot of excess hydrogen adsorbed as a function of both temperature and pressure (a, b and $\mathrm{c}$ ) as well as the corresponding T-P contour lines ( $\mathrm{d}$, e and $\mathrm{f}$ ) for the CACs MSC30, SA20 and Filtrasorb400, respectively. The use of lower temperatures allows reducing the pressure to get maximum hydrogen storage. The slope of the contour lines increases as the temperature is lowered, due to the increased density of adsorbed hydrogen 46,56,57, which is the most important contribution to hydrogen storage under supercritical conditions ${ }^{58}$. Figures $3 \mathrm{~d}, 3 \mathrm{e}$ and $3 \mathrm{f}$ show that the values of the excess hydrogen adsorbed are higher than 5, 3 and 2 wt. $\%$ for MSC30, SA20 and Filtrasorb400, respectively, at temperatures lower than $93 \mathrm{~K}$ and pressures between 2 and $8 \mathrm{MPa}$. 

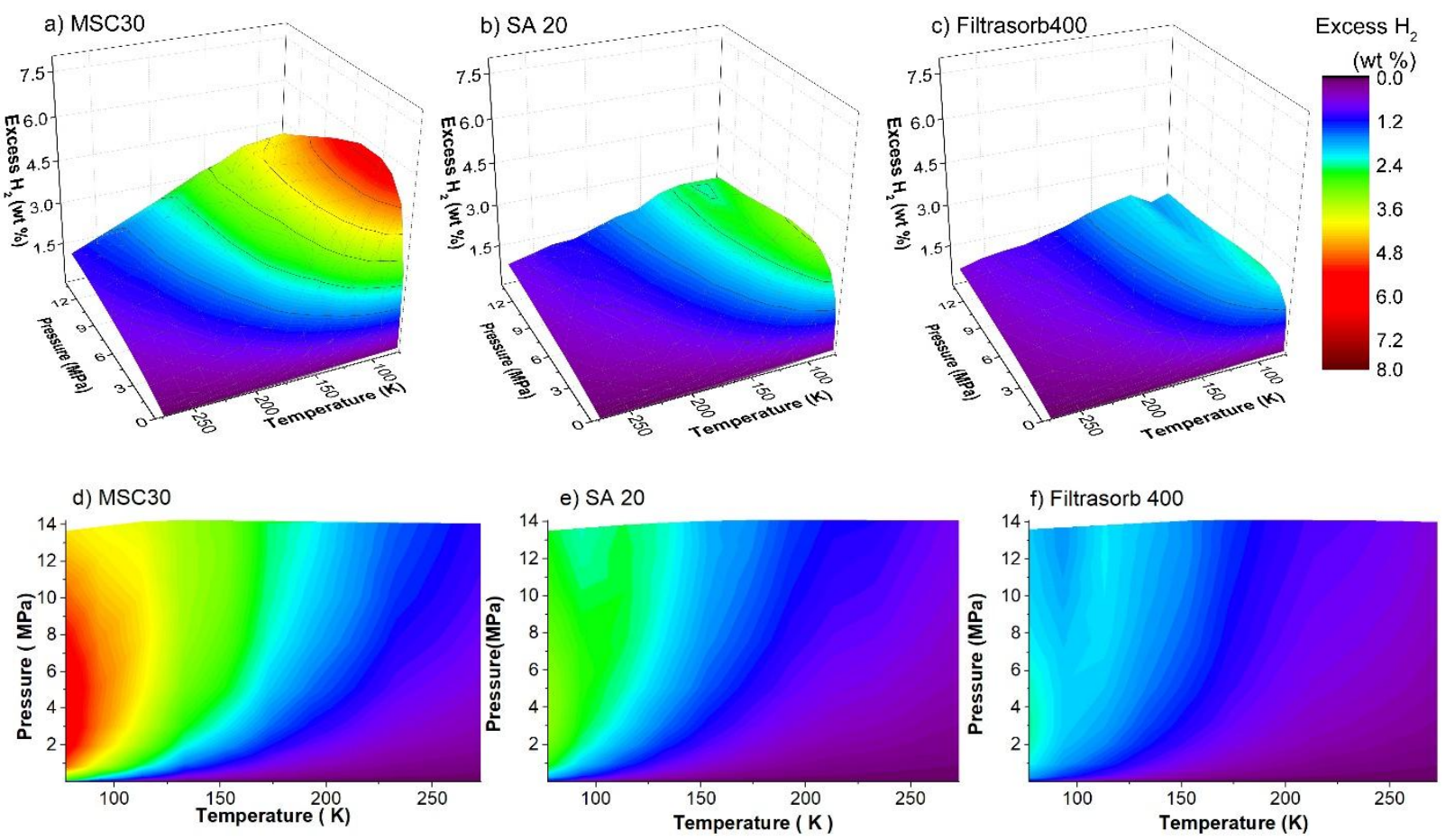

Figure 3. Excess hydrogen adsorbed plotted as a function of pressure and temperature for: (a) MSC30, (b) SA20 and (c) Filtrasorb400; and contour lines of the previous 3D representations for: (d) MSC30, (e) SA20 and (f) Filtrasorb400. 

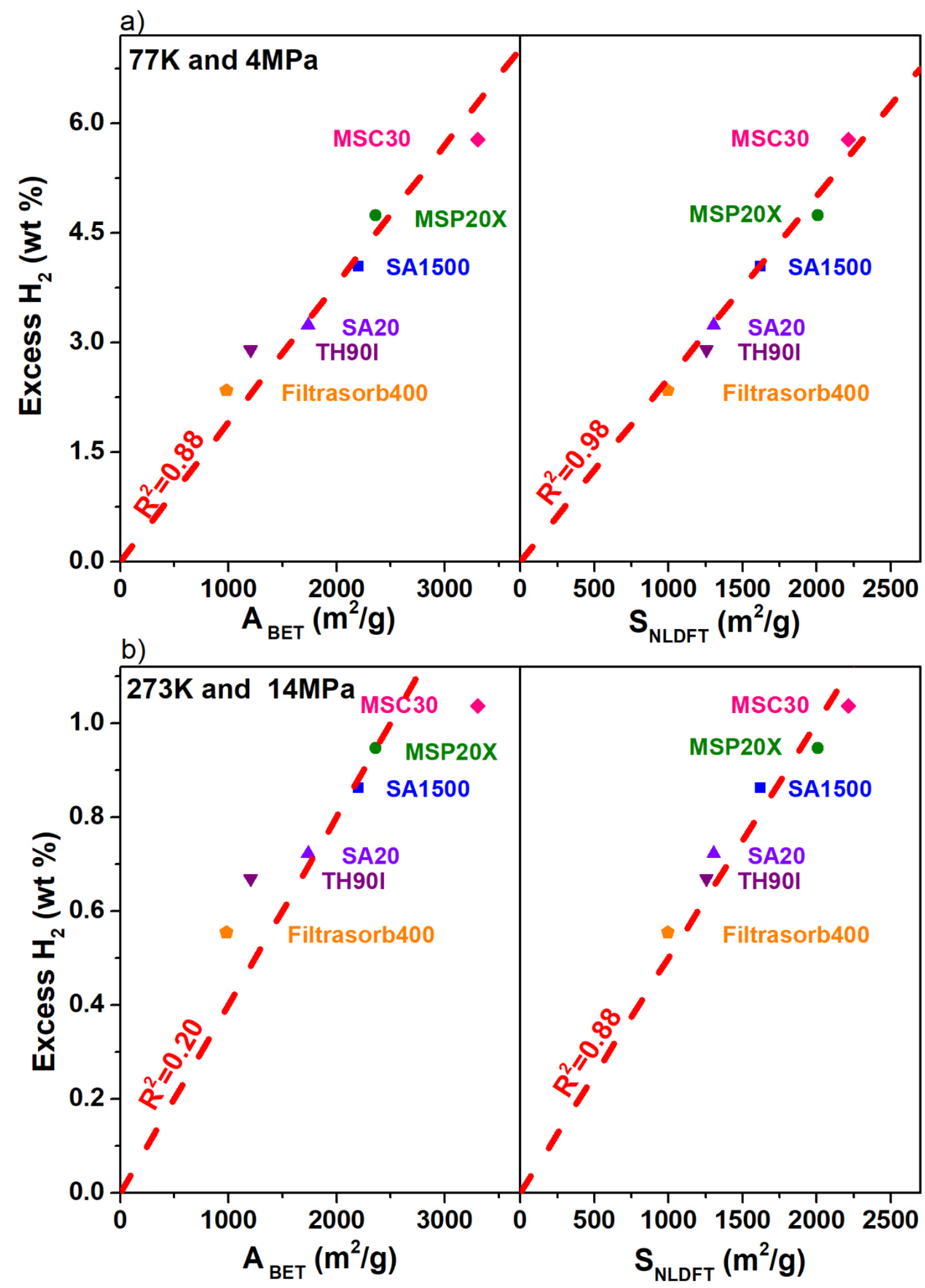

Figure 4. Hydrogen excess adsorbed as a function of $A_{B E T}$ or $S_{N L D F T}$ at: (a) $77 \mathrm{~K}$ and $4 \mathrm{MPa}$ (value for Filtrasorb400 corresponds to $3 \mathrm{MPa}$ ); and (b) 273K and $14 \mathrm{MPa}$. The dashed lines (---) correspond to the linear regression fit through the origin at $(0,0)$. 
Figure 4 shows the excess hydrogen adsorbed, $n_{e x c}$, as a function of $A_{B E T}$ and $S_{N L D F T}$ at 77 and $273 \mathrm{~K}$ for the six CACs. In Figure $4 \mathrm{a}$, the fitting of $n_{\text {exc }}$ as a function of the surface area with a straight line forced to pass through $(0,0)$, showed determination coefficients $\left(\mathrm{R}^{2}\right)$ of 0.88 and 0.98 for $A_{B E T}$ and $S_{N L D F T}$, respectively, at $77 \mathrm{~K}$. Therefore, the fit of the data was more accurate when using $S_{N L D F T}$. Indeed, hydrogen adsorption at $77 \mathrm{~K}$ was found to increase by 1.25 wt. $\%$ per $500 \mathrm{~m}^{2} \mathrm{~g}^{-1}$ of $S_{N L D F T}$, which could be proposed as an alternative to the Chahine rule ${ }^{14,25}$. Figure $4 \mathrm{~b}$ shows that the difference between the determination coefficients obtained at the linear fitting of $n_{e x c}$ as a function of $S_{N L D F T}$ and $A_{B E T}$ at $273 \mathrm{~K}$ and $14 \mathrm{MPa}$ were even higher. The $\mathrm{R}^{2}$ obtained by the linear regression passing though $(0,0)$ were 0.20 and 0.88 for $A_{B E T}$ and $S_{N L D F T}$, respectively. The higher $\mathrm{R}^{2}$ obtained using $S_{N L D F T}$ at both $77 \mathrm{~K}$ and $273 \mathrm{~K}$ clearly shows that a more accurate characterization of the textural properties was achieved using both $\mathrm{CO}_{2}$ and $\mathrm{N}_{2}$ adsorption isotherms.

Figure $5 \mathrm{a}$ and $5 \mathrm{~b}$ show the excess hydrogen adsorption at $77 \mathrm{~K}$ up to 100 and $1.5 \mathrm{kPa}$, respectively. The excess hydrogen adsorbed was found to be higher in the CACs having both high microporosity and very narrow pores, i.e., Filtrasorb400, MSPX 20 and TH90I. Indeed, Van der Waals interactions are stronger in the ACs with narrow pores, as they overlap when hydrogen molecules are in contact with both pore walls ${ }^{59}$. According to this, the Henry's constant linearly increases when reducing the average micropore size (Figure 5c), confirming that hydrogen adsorption is enhanced in very narrow pores where adsorption is stronger due to overlapping adsorption potentials. 

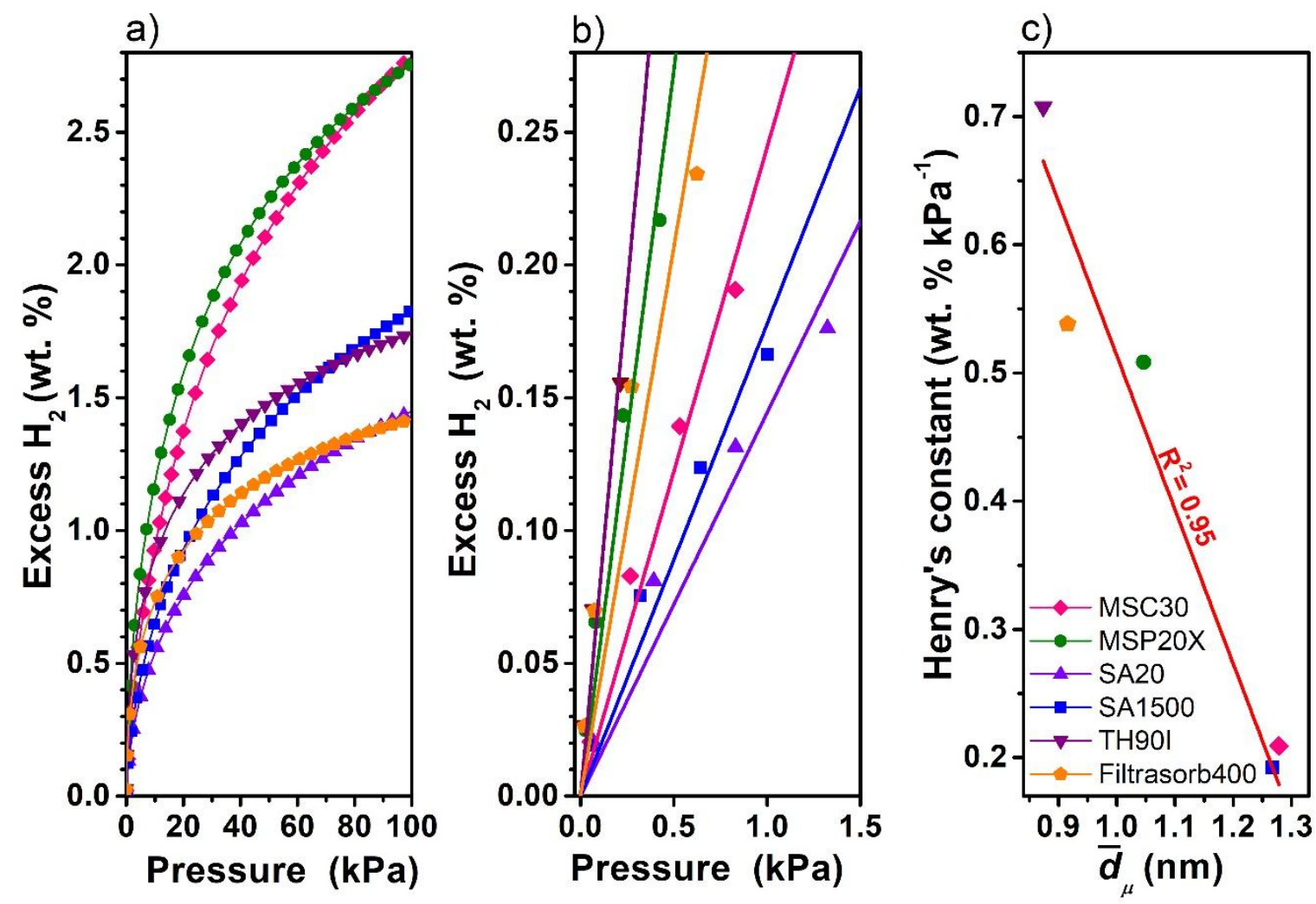

Figure 5. Hydrogen isotherms for the six CACs at $77 \mathrm{~K}$ : (a) up to $100 \mathrm{kPa}$; and (b) up to 1.5 $\mathrm{kPa}$. (c) Henry's constant as a function of average micropore size. The legend in (c) also applies to (a) and (b).

\subsection{Fitting with the MDA equation}

Figure 6 shows that the MDA equation is a good analytical tool to describe hydrogen adsorption data over a wide range of pressures and temperatures. Data were reported for two of the six CACs studied in the present paper, i.e., SA20 and SA 1500. The five parameters of the MDA equation (i.e., $n_{\max }, \alpha, \beta, P_{0}$ and $V_{a}$ ) obtained by non-linear regression of the hydrogen adsorption data are listed in Table $\mathrm{S} 2$ of the Supporting Information. $\mathrm{R}^{2}$ coefficients ranging from 0.96 to 0.99 were obtained for all six CACs. 

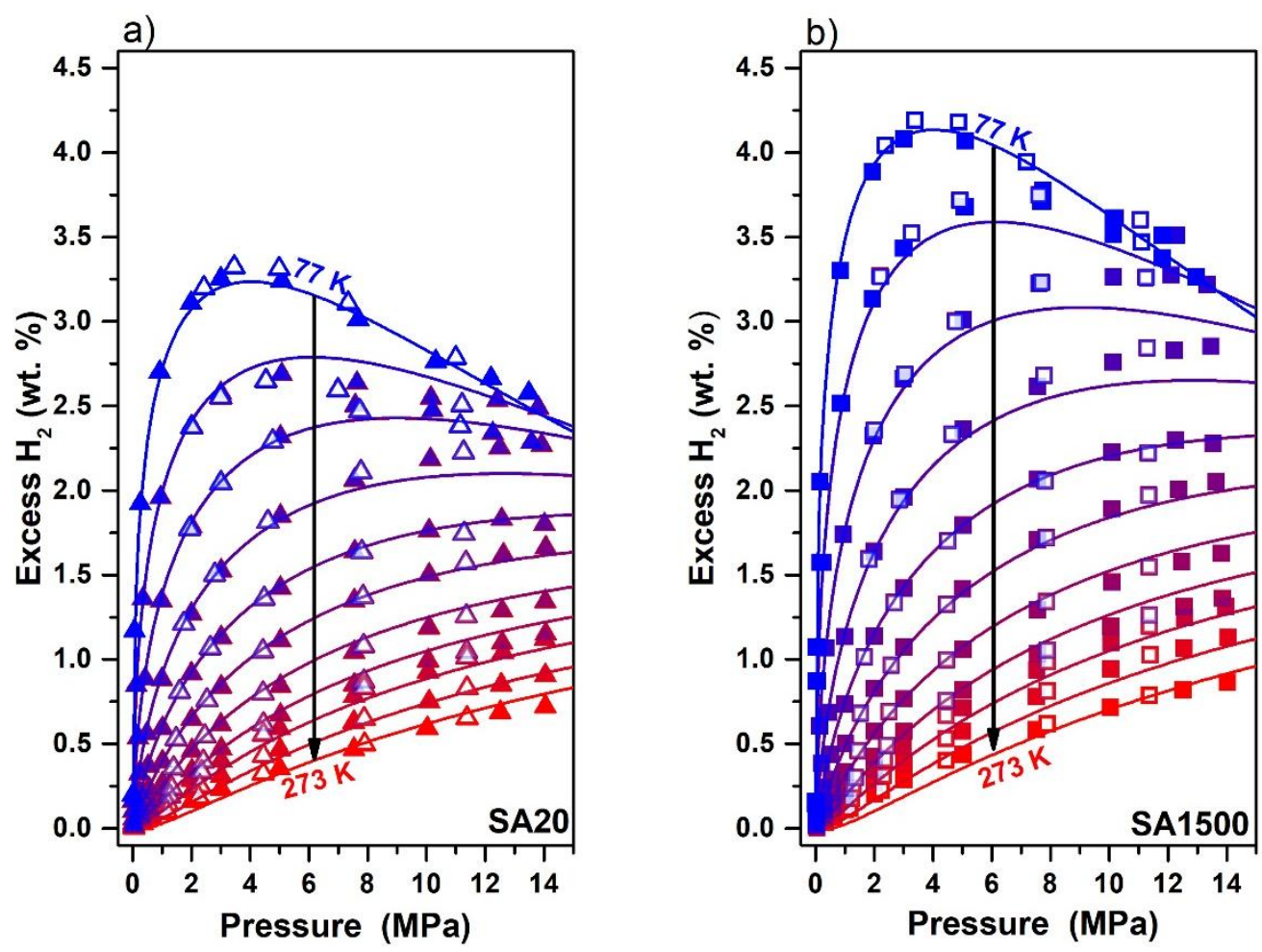

Figure 6. Hydrogen isotherms on: (a) SA20; and (b) SA1500, and their fitting with the MDA equation at 77, 93, 113, 133, 153, 173, 193, 213, 233, 253 and 273 K. Full and empty symbols indicate adsorption and desorption data, respectively.

Figure 7a shows the almost perfect linear variation of $V_{a}$ with $A_{B E T}\left(\mathrm{R}^{2}=99\right) . V_{a}$ ranged from $1.50 \mathrm{~cm}^{3} \mathrm{~g}^{-1}$ for MSC30 to $0.362 \mathrm{~cm}^{3} \mathrm{~g}^{-1}$ for Filtrasorb400. The linear correlations between $V_{a}$ and $S_{N L D F T}$, micropore volume and total pore volume, were also calculated and showed lower determination coefficients, i.e., 0.90, 0.91 and 0.7, respectively (see Table S3). The fact that $V_{a}$ is more dependent on $A_{B E T}$ than on $S_{N L D F T}$ clearly suggests that hydrogen storage is not exclusively a surface phenomenon; hydrogen storage also takes place by pore filling as it occurs during nitrogen adsorption at $77 \mathrm{~K}$. Since $A_{B E T}$ is an apparent area that takes into account not only the surface coverage but also the pore filling, $V_{a}$ and $A_{B E T}$ evolve 
in the same way ${ }^{60}$. Figure 7 a also shows the variation of $n_{\max }$ as a function of $A_{B E T}$ : a linear relationship was found $\left(R^{2}=0.98\right) . n_{\max }$ varied between 72.5 and $20.8 \mathrm{~mol} \mathrm{~kg}{ }^{-1}$.
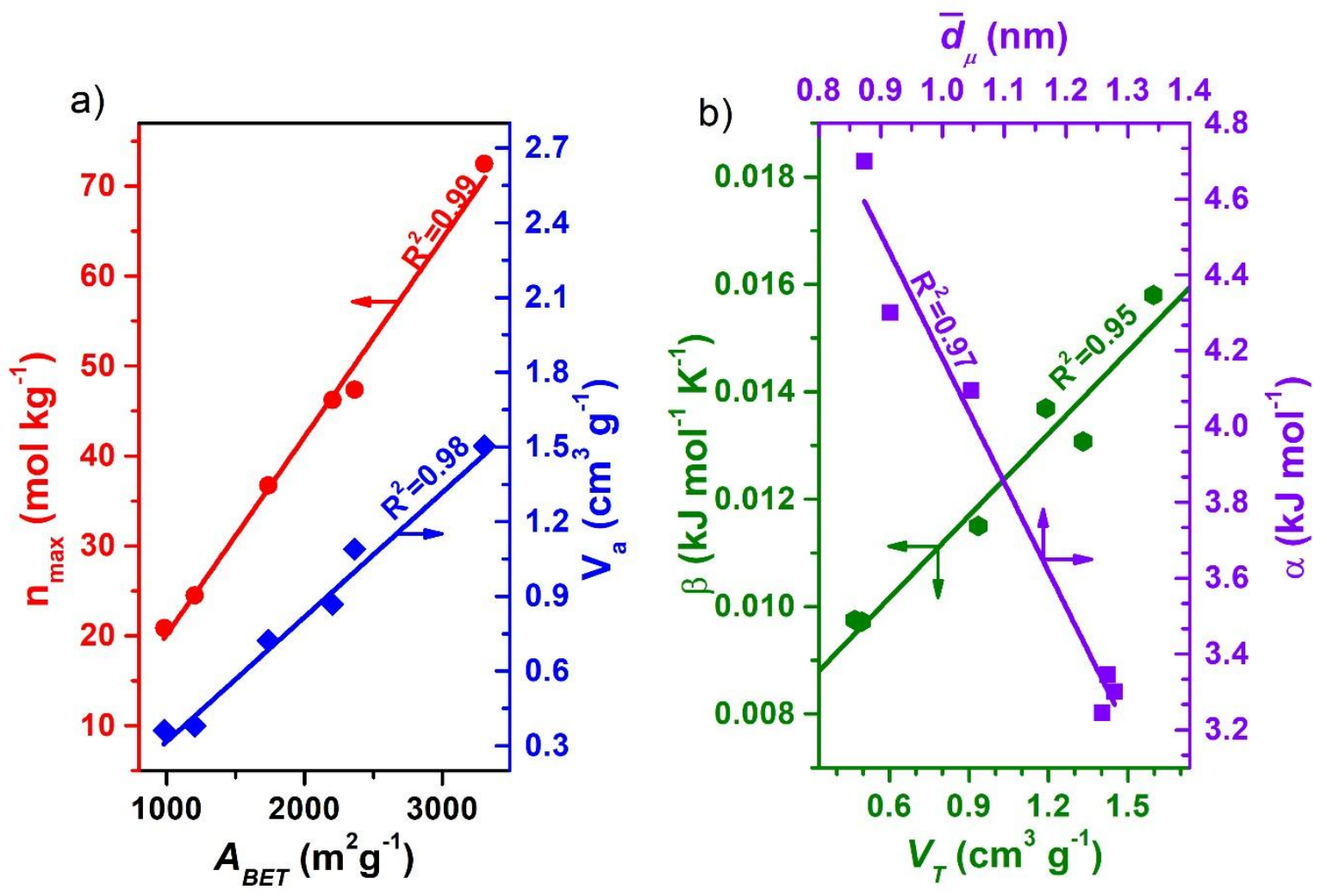

Figure 7. MDA parameters plotted as a function of several textural parameters: (a) $V_{a}$ and $n_{\max }$ as a function of $A_{B E T}$; (b) $\alpha$ as a function of the average micropore size, and $\beta$ as a function of the total pore volume.

Figure $7 \mathrm{~b}$ shows the "enthalpy" factor, $\alpha$, as a function of the average micropore size. $\alpha$ decreases linearly as the average micropore diameter increases $\left(\mathrm{R}^{2}=0.97\right)$. This behavior is due to the fact that the interactions between hydrogen molecules and the walls of narrower pores in the AC are stronger. Indeed, $\alpha$ is related to the heat of adsorption as shown by Eq. (3). Thus, the more hydrogen is adsorbed in a pore, the higher the heat released will be, due to the exothermic nature of hydrogen adsorption on ACs. Figure $7 \mathrm{~b}$ also shows the linear $\left(\mathrm{R}^{2}=0.95\right)$ and direct relationship of the "entropy" factor, $\beta$, with the total pore volume, $V_{T}$. In contrast to $\alpha, \beta$ was found to increase with the average pore size. This behavior can be 
explained by the higher degree of disorder of hydrogen molecules, and therefore by a higher entropy, in wider pores.

Concerning the pseudo-saturation pressure, $P_{0}$, the highest value was found for MSC30: $1013 \mathrm{MPa}$, and values ranging from 616 to $700 \mathrm{MPa}$ were obtained for other CACs. Richard et al. ${ }^{29}$ reported values of $71.6 \mathrm{~mol} \mathrm{~kg}{ }^{-1}$ and $1470 \mathrm{MPa}$ for $n_{a d s}$ and $P_{0}$, respectively, with the AC AX-21 (former name of the MSC30), which are close to those obtained in this study, 72.5 mol kg ${ }^{-1}$ and $1013 \mathrm{MPa}$ for MSC30. Nevertheless, these differences may be explained by the different maximum pressures reached for the measurements (14 MPa in this study, $6 \mathrm{MPa}$ by the aforementioned authors), which inevitably affects the non-linear regression giving a lower coefficient of determination, $\mathrm{R}^{2}$. In addition, it is important to highlight that even though they are supposed to be the same, they had different values of BET area $\left(A_{B E T}\right.$ of $3300 \mathrm{~m}^{2} \mathrm{~g}^{-1}$ and $2800 \mathrm{~m}^{2} \mathrm{~g}^{-1}$ for MSC30 and AX-21, respectively).

In the original model proposed by Dubinin, $P_{0}$ represented the saturation pressure ${ }^{44}$. Indeed, Dubinin's model was developed to describe adsorption of gases under subcritical conditions. However, hydrogen adsorption generally occurs under supercritical conditions, and the original definition of $P_{0}$ therefore loses its physical meaning. Do and Do support a concept of quasi-saturated vapor pressure based on the assumption that supercritical fluids might form clusters when confined in narrow micropores, and these clusters might be large enough to exert a $P_{0}$ in the same way as a subcritical fluid ${ }^{46}$. According to this, $P_{0}$ should be temperature-dependent and be a characteristic property of any adsorbent material. Amankwab and Schwakz ${ }^{61}$ proposed that $P_{0}$ can be defined as:

$$
P_{0}=P_{c}\left(T / T_{c}\right)^{k}
$$

where $P_{c}$ and $T_{c}$ are critical pressure and temperature, respectively, $T$ is the process temperature, and $k$ is a factor that depends on the adsorbate-adsorbent interactions and is 
generally set at 2 for $\mathrm{H}_{2}$ adsorption on ACs ${ }^{29,41,42}$. Other authors have suggested that $P_{0}$ depends not only on the adsorbed gas, but also on the nature of the adsorbent, and values of $k$ ranging between 2 and 4 have been commonly obtained ${ }^{62,63}$. Presently, due to the lower values of determination coefficients (see Table S3), it is not possible to elucidate the dependence of $P_{0}$ with texture, probably because we should also take into account its variation with $T$. This approach will be addressed in further studies.

\subsection{Determination of the isosteric heat of adsorption}

Figure 8a shows the isosteric heat of adsorption calculated from $\alpha$ by Eq. (3), $Q_{s t}^{M D A}$, as a function of the fractional filling, $\Theta=n_{a b s} / n_{\max }$. At low $\Theta$, the first sites to be occupied are those where there are the strongest interactions between the AC surface and the gas, mainly ultramicropores. As $\Theta$ increases, hydrogen adsorption occurs in wider pores where the interaction is less strong ${ }^{47,64}$. Eq. (3) is not appropriate for calculating $Q_{s t}^{M D A}$ when $\Theta$ approaches 0 and 1 , since $Q_{s t}^{M D A}$ increases indefinitely or becomes zero, respectively.

Figure $8 \mathrm{~b}$ shows $Q_{s t}^{M D A}$ as a function of the average micropore size and for different $\Theta$, from 0.01 to 0.94 . A linear dependence $\left(R^{2}=0.98\right)$ of $Q_{S t}^{M D A}$ on the average micropore size was observed for all values of $\Theta$. The $Q_{s t}^{M D A}$ is more dependent on the average micropore size than on the pore volume, as shown in Figure S1 of the Supporting Information. The dependency of $Q_{s t}^{M D A}$ on the average micropore size is much higher at low $\Theta$ because almost the whole surface and micropores are available. At $\Theta=0.001, Q_{s t}^{M D A}$ decreased from 11.37 to $8.52 \mathrm{~kJ}$ $\mathrm{mol}^{-1}$ when the average micropore size increased from 0.86 to $1.26 \mathrm{~nm}$. At $\Theta=0.94, Q_{s t}^{M D A}$ decreased from 1.01 to $0.75 \mathrm{~kJ} \mathrm{~mol}^{-1}$ in the same range of average micropore size. This small variation is due to the fact that the narrowest pores, giving the highest adsorption energies, are already occupied. 

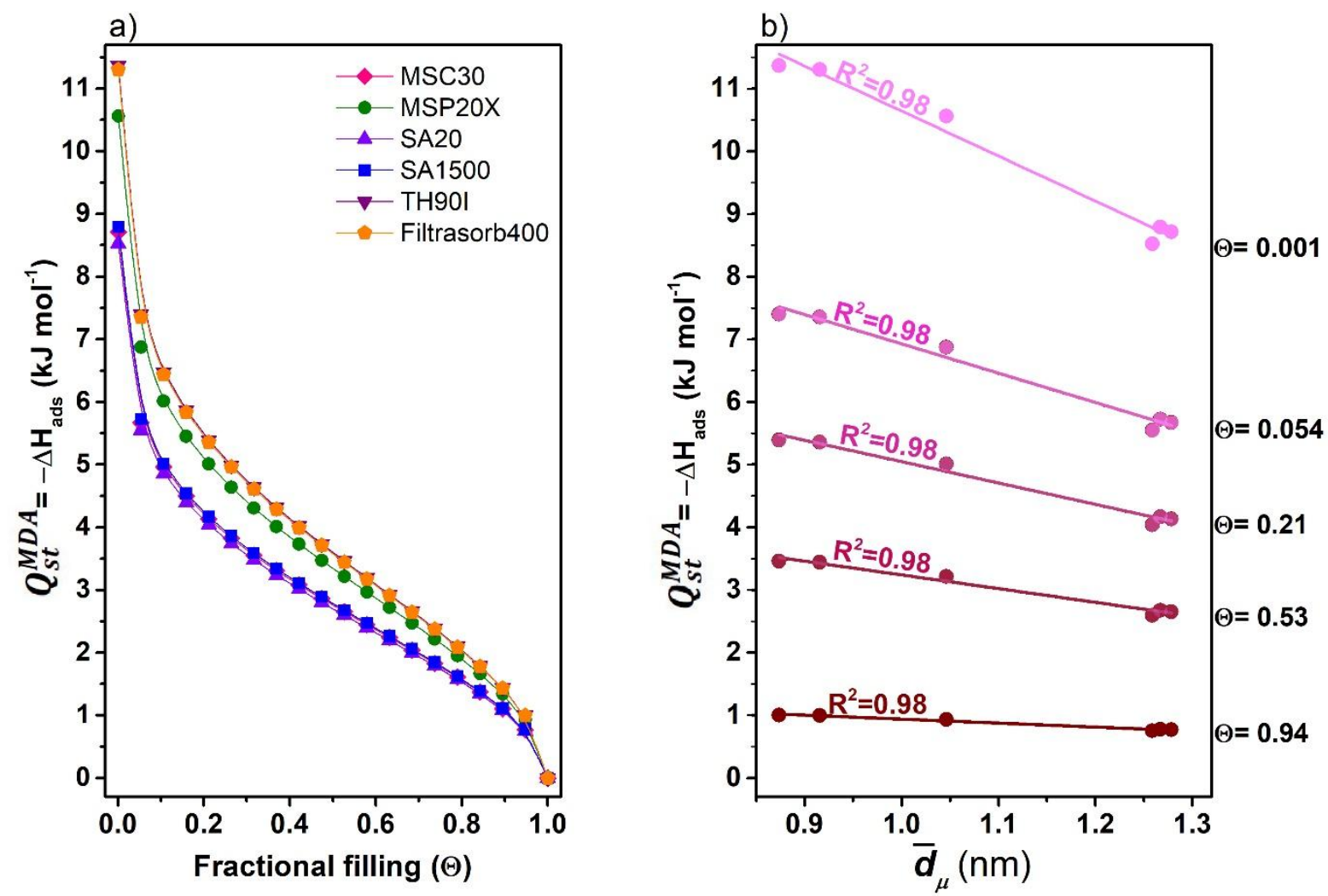

Figure 8. Evolution of $Q_{s t}^{M D A}$ as a function of: (a) fractional filling; and (b) average micropore size for several fractional fillings.

The maximum absolute $\mathrm{H}_{2}$ adsorbed at $77 \mathrm{~K}$ was $7.5,6.2,5.6,3.9,3.5,3.3$ wt. $\%$ for MSC30, MSP20X, SA1500, SA20, TH90 and Filtrasorb400, respectively. As an example, Figure S2 of the Supporting Information shows the isotherms of absolute hydrogen adsorbed for SA20 and SA1500 as a function of fugacity. The Sips parameters for all the CACs are reported in Table S4. These isotherms were used to calculate $Q_{s t}$ using the ClausiusClapeyron equation (Eq. (7)). Figures 9a and 9b show the $Q_{s t}$ obtained for SA20 and SA1500. In general, the $Q_{s t}$ ranged from 4 to $10 \mathrm{~kJ} \mathrm{~mol}^{-1}$ for the six CACs. These values are in good agreement with the results obtained with the MDA equation and presented in Figure 8. Figures $9 \mathrm{c}$ and $9 \mathrm{~d}$ show the $Q_{s t}$ at the lowest $(93 \mathrm{~K})$ and highest $(253 \mathrm{~K})$ temperatures for the six CACs. In general, it can be observed that for each isotherm, $Q_{s t}$ is initially high at nearzero filling and decreases with increasing $n_{a b s}$ to a plateau value, which is different for each 
temperature. The $Q_{s t}$ remains constant with the increase of hydrogen adsorption until a given fractional filling (range of pore diameters available at this temperature) is reached. At high $\Theta$, the $Q_{s t}$ increases strongly due to the repulsion forces between the hydrogen molecules in the gas phase and the already adsorbed hydrogen molecules. This increase is not predicted by the MDA equation.
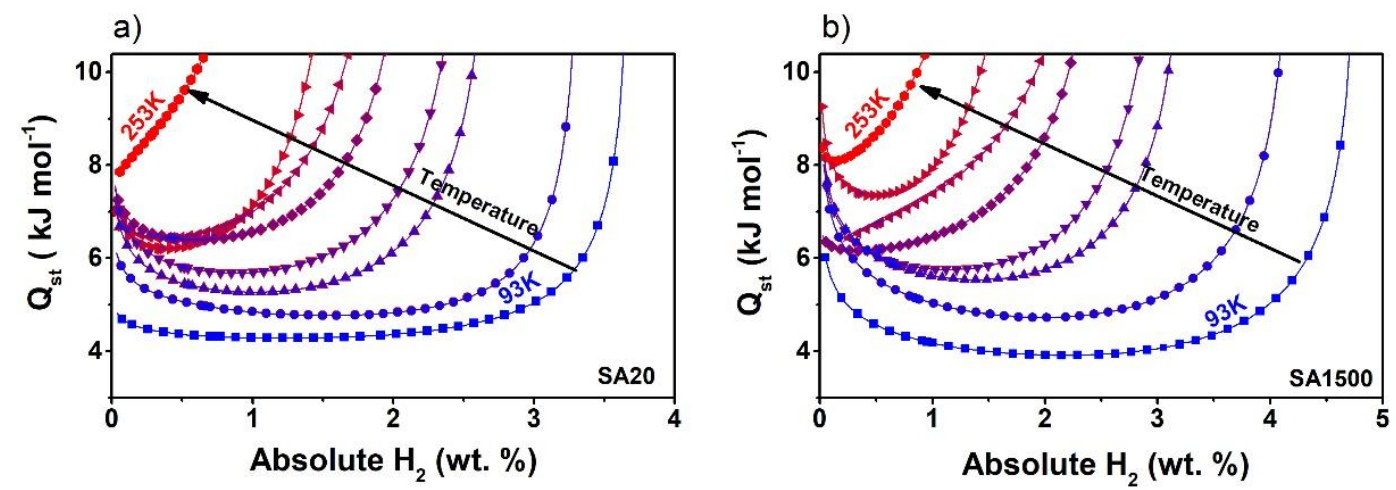

c)
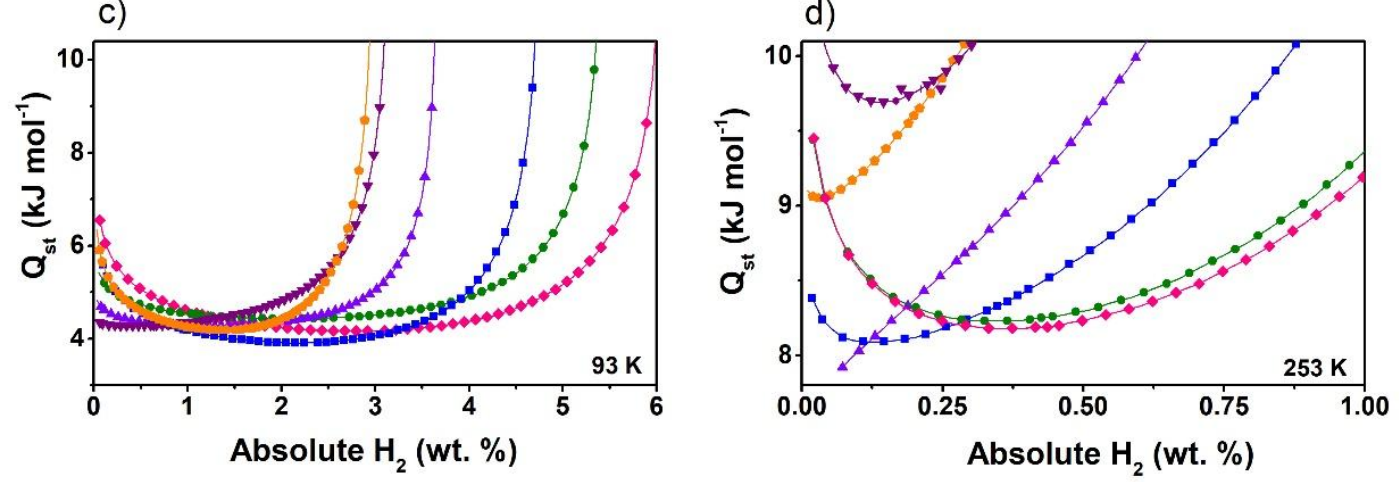

$\because \mathrm{MSC} 30 \quad \longrightarrow \mathrm{MSP} 20 \mathrm{X}$

$\rightarrow$ SA2O

$\because$ SA1500 $\rightarrow$ TH9OI

Filtrasorb400

Figure 9. Isosteric heat of adsorption for the studied temperatures for: (a) SA20; and (b) SA1500; and isosteric heat of the six CACs at: (c) $93 \mathrm{~K}$; and (d) $253 \mathrm{~K}$.

\subsection{Determination of the entropies of adsorption}

For all six CACs, the values of $-\Delta S_{a d s}^{M D A}$ ranged from 0 to $4.5 \mathrm{~kJ} \mathrm{~kg}^{-1} \mathrm{~K}^{-1}$ when Eq. (8) was used. The negative values of $\Delta S_{a d s}^{M D A}$ are consistent with the exothermic nature of hydrogen adsorption ${ }^{31}$. Figure 10a shows the linear increase of $-\Delta S_{a d s}^{M D A}$ as a function of fractional 
filling due to the higher density of the molecules adsorbed in the pores, increasing their filling. The possibilities of movement (disorder) in the pore space decrease, and thus $-\Delta S_{a d s}^{M D A}$ increases. Figure $10 \mathrm{~b}$ shows that $-\Delta S_{a d s}^{M D A}$ is directly proportional to the micropore volume, and the slope of the lines become steeper as the fractional filling increases. The proportionality with $A_{B E T}$ is due to the fact that high-pressure adsorption is mainly by pore filling, so with increasing $A_{B E T}$, adsorption increases and therefore more molecules pass from the gas phase to the adsorbed phase, which is a more ordered state.
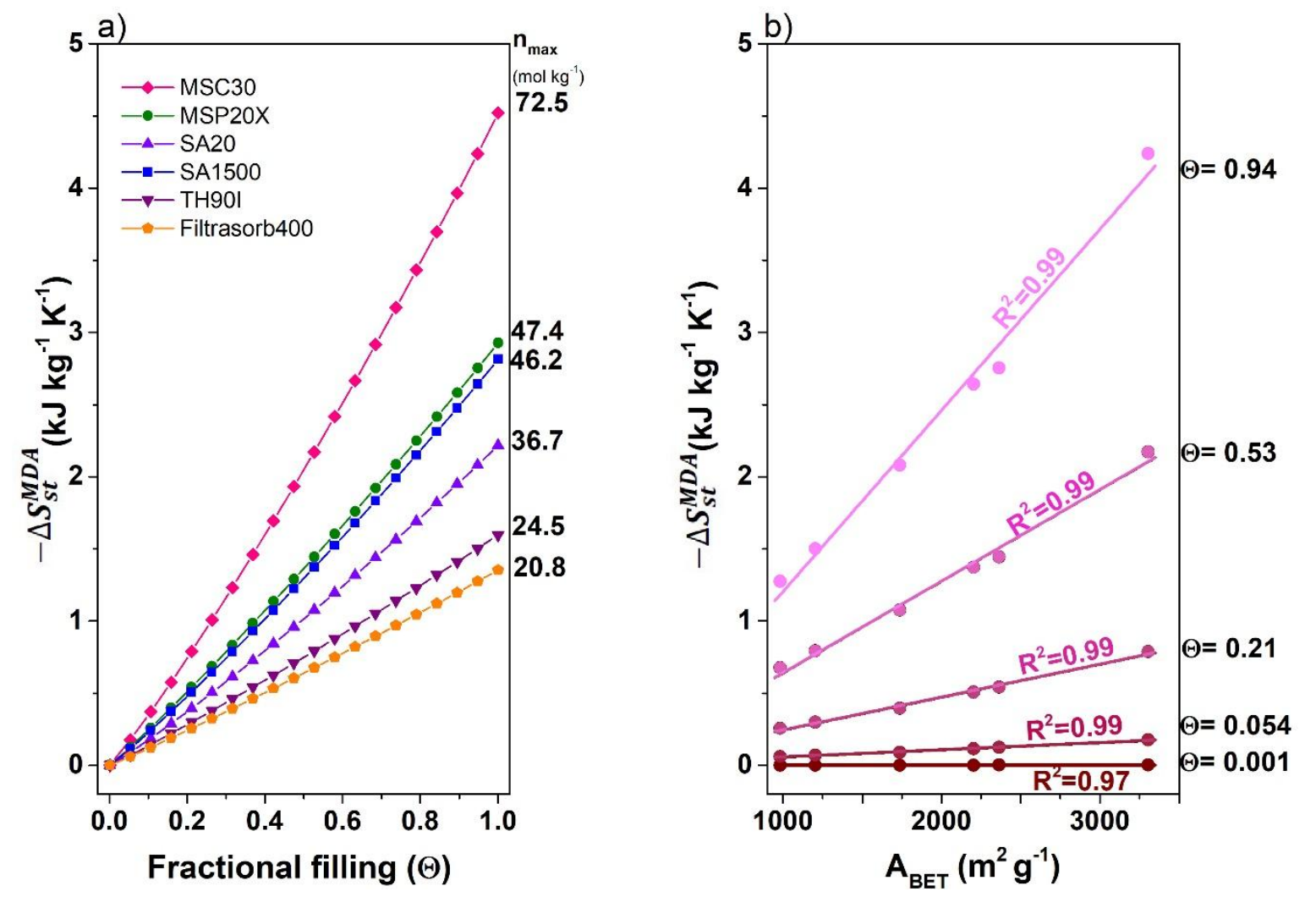

Figure 10. $-\Delta S_{\text {ads }}^{M D A}$ calculated from $\beta$, as a function of: (a) the fractional filling; and (b) the BET area for several fractional fillings.

The MDA equation is not suitable for determining the temperature dependence of the adsorption entropy ${ }^{47,65}$. Thus, $-\Delta S_{a d s}$ was also calculated using the Clausius-Clapeyron (Eq. (9)), considering averaged $Q_{s t}$. Figure S3 shows the average isosteric entropy of adsorption of 
the six CACs as a function of temperature, considering small amounts of adsorbed hydrogen (0-3.5 mmol g $\left.\mathrm{g}^{-1}\right) .-\Delta S_{a d s}$ values obtained for the six carbons are in good agreement with those reported in the literature for hydrogen adsorption on: $\mathrm{ACs}{ }^{42,64}$, MOFs ${ }^{11,66}$ and zeolites ${ }^{67}$. For all the CACs, the value of $-\Delta S_{a d s}$ decreased when the temperature increased. This can be attributed to the fact that there is no significant change in $Q_{s t}$ at low filling, 5-10 kJ mol${ }^{-1}$, as observed in Figure 9, so the decrease in the $Q_{s t} / T$ ratio is almost entirely due to the increase in temperature, in good agreement with the results reported in the literature ${ }^{64,68}$. Higher values of $-\triangle S_{a d s}$ were found for mostly microporous CACs (TH90I, Filtrasorb400 and MSP20X) due to the higher $Q_{s t}$ in narrow pores compared to CACs with a large mesopore fraction (MSC30, SA1500 and SA20).

\subsection{Implementation of the MDA equation in practice}

In this study, we showed for the first time the relationship between MDA parameters and the textural properties of ACs. Although scientifically this may be interesting and intellectually rewarding for the authors of this manuscript, one may question the applicability of the knowledge gained on the dependence of MDA parameters in practice. While we have clearly shown that $\alpha$ and $\beta$ are well correlated with $\bar{d}_{\mu}$ and $V_{T}$, we will now show the effect of each parameter on $n_{a b s} / n_{\max }$ when the temperature varies, and its practical implications.

Figures 11a and 11b show the effect of $\alpha$ and $\beta$ on the fractional filling, $\Theta=n_{a b s} / n_{\max }$, when the temperature increases from 77 to $273 \mathrm{~K}, P / P_{0}$ being set to 0.02 . In Figure $11 \mathrm{a}, \alpha$ was set to $4.2 \mathrm{~kJ} \mathrm{~mol}^{-1}\left(\bar{d}_{\mu}\right.$ around $1.0 \mathrm{~nm}$ ) and $\beta$ varied from 0.02 to $0.01 \mathrm{~kJ} \mathrm{~mol}^{-1} \mathrm{~K}^{-1}$ (equivalent to $V_{T}$ between 2.0 and $0.5 \mathrm{~cm}^{3} \mathrm{~g}^{-1}$ ). Since $n_{\max }$ is directly proportional to $A_{B E T}$ and $V_{\text {micro }}{ }^{60}$, comparing different values of $\beta$ (proportional to $V_{T}$ ) is equivalent to comparing carbons with similar $V_{\text {micro }}$ but with different values of $V_{\text {meso }}$. In Figure $11 \mathrm{~b}, \beta$ was set to $0.01 \mathrm{~kJ} \mathrm{~mol}^{-1} \mathrm{~K}^{-1}$ 
(equivalent to $V_{T}$ equal to $0.5 \mathrm{~cm}^{3} \mathrm{~g}^{-1}$ ) and $\alpha$ varied from 5.8 to $2.5 \mathrm{~kJ} \mathrm{~mol}^{-1}$ (equivalent to $\bar{d}_{\mu}$ between 0.5 and $1.5 \mathrm{~nm}$ ). Comparing the effect of the two parameters on the decrease in fractional filling with the temperature (Figures 11a and 11b), the changes in $\beta$ (function of $V_{T}$ ) were found to be less relevant than the changes in $\alpha$ (function of $\bar{d}_{\mu}$ ).
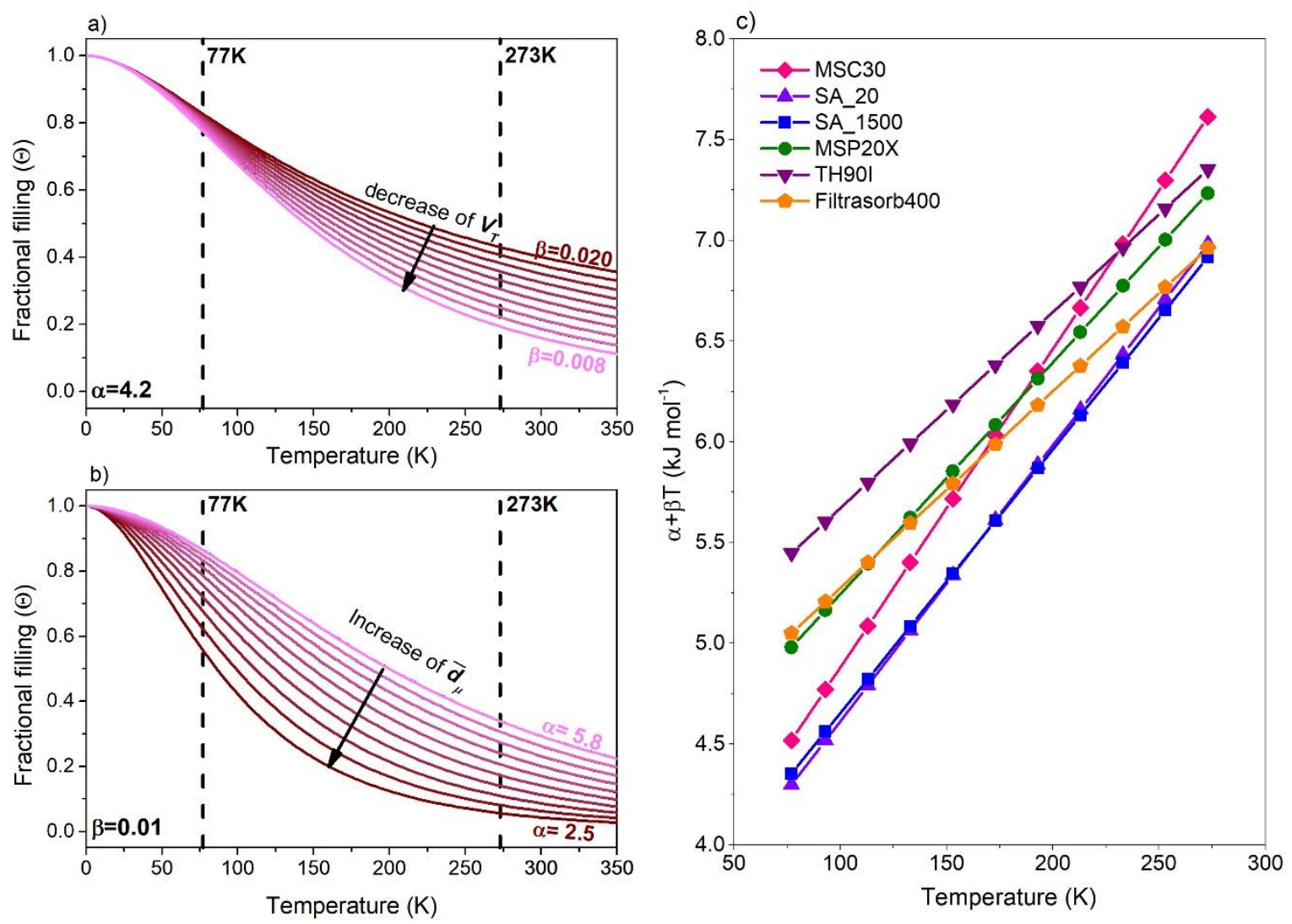

Figure 11. Effect of the parameters: (a) $\beta$; and (b) $\alpha$ on the $\mathrm{H}_{2}$ adsorption capacity at $P / P_{0}=$ 0.02 at different temperatures; (c) sum of enthalpy and entropy contributions as a function of temperature.

According to Myres and Monson ${ }^{65}$, the characteristic energy of adsorption can be obtained by the sum of enthalpy and entropy contributions, $\alpha+\beta T$, which can be interpreted as an average excess of adsorption energy in the pores compared to the open surface ${ }^{47,69,70}$. Bickford et al. ${ }^{70}$ associated this parameter with the influence of the adsorbent surface chemistry in the adsorption of $\mathrm{CO}_{2}$ and $\mathrm{N}_{2}$. Figure 11c shows $\alpha+\beta T$ as a function of the 
temperature for the six CACs. Due to its very high $V_{T}$, MSC30 exhibited the largest variation in the function $\alpha+\beta \mathrm{T}$ when increasing the temperature from 77 to $273 \mathrm{~K}$.

Since $\alpha$ is inversely proportional to $\bar{d}_{\mu}$ and $\beta$ is proportional to $V_{T}$, the adsorption of hydrogen on a carbon material with a high $V_{T}$, basically consisting of narrow micropores, would be less temperature-dependent. In this way, $\bar{d}_{\mu}$ and $V_{T}$ play a role not just on the total adsorption capacity ${ }^{60}$ but also on the reduction of the effect of temperature on adsorption, which is highly desirable for hydrogen storage where desorption is achieved by lowering the pressure. However, this is far from being the best option for temperature-driven hydrogen compression where the pressure increase is mainly due to changes in adsorption capacity with the temperature. In conclusion, for ACs having equivalent values of $A_{B E T}$, and taking into account hydrogen capacities on a weight basis $\left(\mathrm{g} \mathrm{H}_{2} / \mathrm{g}\right.$ AC), those with high $V_{T}$ and narrow $\bar{d}_{\mu}$ should be chosen for hydrogen storage while those with a larger $\bar{d}_{\mu}$ and lower $V_{T}$ and $V_{\text {meso }}$ are better suited to hydrogen compression. Finally, this study should help researchers working on hydrogen storage in ACs to have a preliminary estimation of the hydrogen capacities, after a correct textural characterization of their materials, at different temperatures and pressures.

\section{Conclusions}

The Modified Dubinin-Astakhov (MDA) equation has been successfully used to fit the hydrogen excess adsorption over a wide range of pressures and temperatures and on six commercial activated carbons (CACs): MSC30, MSP20X, SA20, SA1500, Filtrasorb400 and TH90I. Four out of the five parameters of the MDA equation, i.e., $n_{\max }, V_{a}, \alpha$ and $\beta$ were correlated to the textural properties of the CACs. $n_{\max }$ and $V_{a}$ are directly proportional to the BET area. The "entropy" factor, $\beta$, linearly increased with the total pore volume whereas the "enthalpy" factor, $\alpha$, was inversely proportional to the average micropore diameter. 
The isosteric heat of adsorption, $Q_{s t}$, was calculated using the Clausius-Clapeyron equation. Values between 5 and $10 \mathrm{~kJ} \mathrm{~mol}^{-1}$ were obtained for all six CACs, consistent with those obtained using the MDA equation. The adsorption entropy was found to be higher in materials with narrower pores and higher BET areas.

As the variation of hydrogen adsorption capacity with temperature is controlled by the parameters $\alpha$ and $\beta$, we can conclude that hydrogen adsorption on carbon materials with high pore volumes and narrow micropore sizes would be less temperature-dependent. For ACs having equivalent BET areas and taking into account hydrogen capacities on a weight basis ( $\mathrm{g}$ $\mathrm{H}_{2} / \mathrm{g} \mathrm{AC}$ ), those with higher pore volumes and narrower micropores should be chosen for hydrogen storage, while those with wider micropores and lower mesopore volumes are better suited for hydrogen compression. Finally, this study should help researchers working on hydrogen storage on ACs to have a preliminary estimation of the hydrogen capacities, after a correct textural characterization of their materials, at different temperatures and pressures.

\section{Supporting Information}

Textural characteristics of the CACs; MDA parameters of each CAC; determination coefficient when linearly fitting the MDA parameters, the isosteric heat or entropy of adsorption to the textural parameters; SIPS parameters; evolution of $Q_{s t}$ as a function of total pore volume for several fractional fillings; absolute hydrogen adsorption isotherms of: (a) SA20; and (b) SA1500 fitted by the Sips equation; average isosteric entropy of adsorption of the six CAC's as a function of the temperature at low amount adsorbed hydrogen; evolution of the average isosteric entropy of adsorption as a function of the average micropore size over the temperature range $93-253 \mathrm{~K}$. 


\section{Acknowledgements}

The financial support of the CONACYT-SENER scholarship 708651/ 739301 is gratefully acknowledged. This study was partly supported by the French PIA project "Lorraine Université d'Excellence", reference ANR-15-IDEX-04-LUE, the TALiSMAN project funded by FEDER (2019-000214) and the Research Fund for Coal and Steel (RFCS) of the European Union (EU) under grant agreement No 709741 (PROMOTEE project). Ingevity ${ }^{\mathrm{TM}}$ and Silcarbon Aktivkohle ${ }^{\mathrm{TM}}$ are gratefully acknowledged for providing activated carbons. The authors thank Philippe Gadonneix for his technical assistance in the laboratory measurements. 


\section{References}

(1) Sinigaglia, T.; Lewiski, F.; Santos Martins, M. E.; Mairesse Siluk, J. C. Production, Storage, Fuel Stations of Hydrogen and Its Utilization in Automotive Applications-a Review. Int. J. Hydrog. Energy 2017, 42 (39), 24597-24611. https://doi.org/10.1016/j.ijhydene.2017.08.063.

(2) Méndez, F. J.; González-Millán, A.; García-Macedo, J. A. A New Insight into $\mathrm{Au} / \mathrm{TiO} 2-\mathrm{Catalyzed} \mathrm{Hydrogen} \mathrm{Production} \mathrm{from} \mathrm{Water-Methanol} \mathrm{Mixture} \mathrm{Using} \mathrm{Lamps}$ Containing Simultaneous Ultraviolet and Visible Radiation. Int. J. Hydrog. Energy 2019, 44 (29), 14945-14954. https://doi.org/10.1016/j.ijhydene.2019.04.131.

(3) Berry, G. D.; Aceves, S. M. Onboard Storage Alternatives for Hydrogen Vehicles. Energy Fuels 1998, 12 (1), 49-55. https://doi.org/10.1021/ef9700947.

(4) Sdanghi, G.; Maranzana, G.; Celzard, A.; Fierro, V. Review of the Current Technologies and Performances of Hydrogen Compression for Stationary and Automotive Applications. Renew. Sustain. Energy Rev. 2019, 102, 150-170. https://doi.org/10.1016/j.rser.2018.11.028.

(5) Moreno-Blanco, J.; Petitpas, G.; Espinosa-Loza, F.; Elizalde-Blancas, F.; MartinezFrias, J.; Aceves, S. M. The Storage Performance of Automotive Cryo-Compressed Hydrogen Vessels. Int. J. Hydrog. Energy 2019, 44 (31), 16841-16851. https://doi.org/10.1016/j.ijhydene.2019.04.189.

(6) Law, K.; Rosenfeld, J. Cost Analyses of Hydrogen Storage Materials and On-Board Systems; TIAX LLC: Cupertino, California, 2011; p 27.

(7) Andersson, J.; Grönkvist, S. Large-Scale Storage of Hydrogen. Int. J. Hydrog. Energy 2019, 44 (23), 11901-11919. https://doi.org/10.1016/j.ijhydene.2019.03.063.

(8) Meneghelli, B.; Tamburello, D.; Fesmire, J.; Swanger, A. IV.D.4 Integrated Insulation System for Automotive Cryogenic Storage Tanks. 2017, 6.

(9) Bellosta von Colbe, J.; Ares, J.-R.; Barale, J.; Baricco, M.; Buckley, C.; Capurso, G.; Gallandat, N.; Grant, D. M.; Guzik, M. N.; Jacob, I.; Jensen, E. H.; Jensen, T.; Jepsen, J.; Klassen, T.; Lototskyy, M. V.; Manickam, K.; Montone, A.; Puszkiel, J.; Sartori, S.; Sheppard, D. A.; Stuart, A.; Walker, G.; Webb, C. J.; Yang, H.; Yartys, V.; Züttel, A.; Dornheim, M. Application of Hydrides in Hydrogen Storage and Compression: Achievements, Outlook and Perspectives. Int. J. Hydrog. Energy 2019, 44 (15), 77807808. https://doi.org/10.1016/j.ijhydene.2019.01.104.

(10) Farha, O. K.; Eryazici, I.; Jeong, N. C.; Hauser, B. G.; Wilmer, C. E.; Sarjeant, A. A.; Snurr, R. Q.; Nguyen, S. T.; Yazaydın, A. Ö.; Hupp, J. T. Metal-Organic Framework Materials with Ultrahigh Surface Areas: Is the Sky the Limit? J. Am. Chem. Soc. 2012, 134 (36), 15016-15021. https://doi.org/10.1021/ja3055639.

(11) Liu, Y.; Guo, F.; Hu, J.; Zhao, S.; Liu, H.; Hu, Y. Entropy Prediction for H2 Adsorption in Metal-Organic Frameworks. Phys. Chem. Chem. Phys. 2016, 18 (34), 23998-24005. https://doi.org/10.1039/C6CP04645B.

(12) Schaefer, S.; Muñiz, G.; Izquierdo, M. T.; Mathieu, S.; Ballinas-Casarrubias, M. L.; González-Sánchez, G.; Celzard, A.; Fierro, V. Rice Straw-Based Activated Carbons Doped with $\mathrm{SiC}$ for Enhanced Hydrogen Adsorption. Int. J. Hydrog. Energy 2017, 42 (16), 11534-11540. https://doi.org/10.1016/j.ijhydene.2017.02.043.

(13) Tellez-Juárez, M. C.; Fierro, V.; Zhao, W.; Fernández-Huerta, N.; Izquierdo, M. T.; Reguera, E.; Celzard, A. Hydrogen Storage in Activated Carbons Produced from Coals of Different Ranks: Effect of Oxygen Content. Int. J. Hydrog. Energy 2014, 39 (10), 4996-5002. https://doi.org/10.1016/j.ijhydene.2014.01.071. 
(14) Sdanghi, G.; Maranzana, G.; Celzard, A.; Fierro, V. Hydrogen Adsorption on Nanotextured Carbon Materials. In Hydrogen Storage Technologies; John Wiley \& Sons, Ltd, 2018; pp 263-320. https://doi.org/10.1002/9781119460572.ch9.

(15) Cousins, K.; Zhang, R. Highly Porous Organic Polymers for Hydrogen Fuel Storage. Polymers 2019, 11 (4), 690. https://doi.org/10.3390/polym11040690.

(16) Sdanghi, G.; Maranzana, G.; Celzard, A.; Fierro, V. Towards Non-Mechanical Hybrid Hydrogen Compression for Decentralized Hydrogen Facilities. Energies 2020, 13 (12), 3145. https://doi.org/10.3390/en13123145.

(17) Andersson, J.; Grönkvist, S. Large-Scale Storage of Hydrogen. Int. J. Hydrog. Energy 2019. https://doi.org/10.1016/j.ijhydene.2019.03.063.

(18) Ahluwalia, R. K.; Peng, J. K.; Roh, H. S.; Hua, T. Q.; Houchins, C.; James, B. D. Supercritical Cryo-Compressed Hydrogen Storage for Fuel Cell Electric Buses. Int. J. Hydrog. Energy 2018, 43 (22), 10215-10231. https://doi.org/10.1016/j.ijhydene.2018.04.113.

(19) Ahluwalia, R. K.; Hua, T. Q.; Peng, J.-K.; Lasher, S.; McKenney, K.; Sinha, J.; Gardiner, M. Technical Assessment of Cryo-Compressed Hydrogen Storage Tank Systems for Automotive Applications. Int. J. Hydrog. Energy 2010, 35 (9), 4171-4184. https://doi.org/10.1016/j.ijhydene.2010.02.074.

(20) de la Casa-Lillo, M. A.; Lamari-Darkrim, F.; Cazorla-Amorós, D.; Linares-Solano, A. Hydrogen Storage in Activated Carbons and Activated Carbon Fibers. J. Phys. Chem. B 2002, 106 (42), 10930-10934. https://doi.org/10.1021/jp014543m.

(21) Fierro, V.; Zhao, W.; Izquierdo, M. T.; Aylon, E.; Celzard, A. Adsorption and Compression Contributions to Hydrogen Storage in Activated Anthracites. Int. J. Hydrog. Energy $2010, \quad 35 \quad$ (17), https://doi.org/10.1016/j.ijhydene.2010.06.004.

(22) Züttel Andreas; Remhof Arndt; Borgschulte Andreas; Friedrichs Oliver. Hydrogen: The Future Energy Carrier. Philos. Trans. R. Soc. Math. Phys. Eng. Sci. 2010, 368 (1923), 3329-3342. https://doi.org/10.1098/rsta.2010.0113.

(23)1b Thommes, M.; Kaneko, K.; Neimark, A. V.; Olivier, J. P.; Rodriguez-Reinoso, F.; Rouquerol, J.; Sing, K. S. W. Physisorption of Gases, with Special Reference to the Evaluation of Surface Area and Pore Size Distribution (IUPAC Technical Report). Pure Appl. Chem. 2015, 87 (9-10), 1051-1069. https://doi.org/10.1515/pac-2014-1117.

(24) Fierro, V.; Szczurek, A.; Zlotea, C.; Marêché, J. F.; Izquierdo, M. T.; Albiniak, A.; Latroche, M.; Furdin, G.; Celzard, A. Experimental Evidence of an Upper Limit for Hydrogen Storage at 77K on Activated Carbons. Carbon 2010, 48 (7), 1902-1911. https://doi.org/10.1016/j.carbon.2010.01.052.

(25) Bénard, P.; Chahine, R. Storage of Hydrogen by Physisorption on Carbon and Nanostructured Materials. Scr. Mater. 2007, $56 \quad$ (10), 803-808. https://doi.org/10.1016/j.scriptamat.2007.01.008.

(26) Ahluwalia, R. K.; Peng, J. K. Automotive Hydrogen Storage System Using CryoAdsorption on Activated Carbon. Int. J. Hydrog. Energy 2009, 34 (13), 5476-5487. https://doi.org/10.1016/j.ijhydene.2009.05.023.

(27) Lam, S. T.; Ballinger, R.; Forsberg, C. Modeling and Predicting Total Hydrogen Adsorption in Nanoporous Carbon Materials for Advanced Nuclear Systems. J. Nucl. Mater. 2018, 511, 328-340. https://doi.org/10.1016/j.jnucmat.2018.09.009.

(28) Tedds, S.; Walton, A.; Broom, D. P.; Book, D. Characterisation of Porous Hydrogen Storage Materials: Carbons, Zeolites, MOFs and PIMs. Faraday Discuss. 2011, 151, 75-94; discussion 95-115. https://doi.org/10.1039/c0fd00022a.

(29) Richard, M.-A.; Bénard, P.; Chahine, R. Gas Adsorption Process in Activated Carbon over a Wide Temperature Range above the Critical Point. Part 1: Modified Dubinin- 
Astakhov Model. Adsorption 2009, 15 (1), 43-51. https://doi.org/10.1007/s10450-0099149-x.

(30) Richard, M.-A.; Bénard, P.; Chahine, R. Gas Adsorption Process in Activated Carbon over a Wide Temperature Range above the Critical Point. Part 2: Conservation of Mass and Energy. Adsorption 2009, 15 (1), 53-63. https://doi.org/10.1007/s10450-009-91504.

(31) Sdanghi, G.; Schaefer, S.; Maranzana, G.; Celzard, A.; Fierro, V. Application of the Modified Dubinin-Astakhov Equation for a Better Understanding of High-Pressure Hydrogen Adsorption on Activated Carbons. Int. J. Hydrog. Energy 2019. https://doi.org/10.1016/j.ijhydene.2019.09.240.

(32) Kloutse, A. F.; Zacharia, R.; Cossement, D.; Chahine, R.; Balderas-Xicohténcatl, R.; Oh, H.; Streppel, B.; Schlichtenmayer, M.; Hirscher, M. Isosteric Heat of Hydrogen Adsorption on MOFs: Comparison between Adsorption Calorimetry, Sorption Isosteric Method, and Analytical Models. Appl. Phys. A 2015, 121 (4), 2. https://doi.org/10.1007/s00339-015-9484-6.

(33) Giraldo, L.; Rodriguez-Estupiñán, P.; Moreno-Piraján, J. C. Isosteric Heat: Comparative Study between Clausius-Clapeyron, CSK and Adsorption Calorimetry Methods. Processes 2019, 7 (4), 203. https://doi.org/10.3390/pr7040203.

(34) Broom, D. P.; Webb, C. J.; Fanourgakis, G. S.; Froudakis, G. E.; Trikalitis, P. N.; Hirscher, M. Concepts for Improving Hydrogen Storage in Nanoporous Materials. Int. $\begin{array}{lllll}\text { J. Hydrog. } & \text { Energy }\end{array}$ https://doi.org/10.1016/j.ijhydene.2019.01.224.

(35) Schaefer, S.; Fierro, V.; Izquierdo, M. T.; Celzard, A. Assessment of Hydrogen Storage in Activated Carbons Produced from Hydrothermally Treated Organic Materials. Int. J. Hydrog. Energy 2016, 41 (28), $12146-12156$. https://doi.org/10.1016/j.ijhydene.2016.05.086.

(36) Rouquerol, J.; Llewellyn, P.; Rouquerol, F. Is the Bet Equation Applicable to Microporous Adsorbents? In Studies in Surface Science and Catalysis; Llewellyn, P. L., Rodriquez-Reinoso, F., Rouqerol, J., Seaton, N., Eds.; Characterization of Porous Solids VII; Elsevier, 2007; Vol. 160, pp 49-56. https://doi.org/10.1016/S01672991(07)80008-5.

(37) Jagiello, J.; Ania, C.; Parra, J. B.; Cook, C. Dual Gas Analysis of Microporous Carbons Using 2D-NLDFT Heterogeneous Surface Model and Combined Adsorption Data of N2 and CO2. Carbon 2015, 91, 330-337. https://doi.org/10.1016/j.carbon.2015.05.004.

(38) Jagiello, J.; Olivier, J. P. Carbon Slit Pore Model Incorporating Surface Energetical Heterogeneity and Geometrical Corrugation. Adsorption 2013, 19 (2), 777-783. https://doi.org/10.1007/s10450-013-9517-4.

(39) Hurst, K. E.; Gennett, T.; Adams, J.; Allendorf, M. D.; Balderas-Xicohténcatl, R.; Bielewski, M.; Edwards, B.; Espinal, L.; Fultz, B.; Hirscher, M.; Hudson, M. S. L.; Hulvey, Z.; Latroche, M.; Liu, D.-J.; Kapelewski, M.; Napolitano, E.; Perry, Z. T.; Purewal, J.; Stavila, V.; Veenstra, M.; White, J. L.; Yuan, Y.; Zhou, H.-C.; Zlotea, C.; Parilla, P. An International Laboratory Comparison Study of Volumetric and Gravimetric Hydrogen Adsorption Measurements. ChemPhysChem 2019, 20 (15), 1997-2009. https://doi.org/10.1002/cphc.201900166.

(40) Richard, M.-A.; Cossement, D.; Chandonia, P.-A.; Chahine, R.; Mori, D.; Hirose, K. Preliminary Evaluation of the Performance of an Adsorption-Based Hydrogen Storage System. AIChE J. 2009, 55 (11), 2985-2996. https://doi.org/10.1002/aic.11904.

(41) Hardy, B.; Corgnale, C.; Chahine, R.; Richard, M.-A.; Garrison, S.; Tamburello, D.; Cossement, D.; Anton, D. Modeling of Adsorbent Based Hydrogen Storage Systems. 
$\begin{array}{llllll}\text { Int. } \quad \text { J. Hydrog. Energy 2012, } 37 & \text { (7), 5691-5705. }\end{array}$ https://doi.org/10.1016/j.ijhydene.2011.12.125.

(42) Jakubov, T. S.; Mainwaring, D. E. Modified Dubinin-Radushkevich/DubininAstakhov Adsorption Equations. J. Colloid Interface Sci. 2002, 252 (2), 263-268. https://doi.org/10.1006/jcis.2002.8498.

(43) Momen, G.; Hermosilla, G.; Michau, A.; Pons, M.; Firdaous, M.; Marty, Ph.; Hassouni, K. Experimental and Numerical Investigation of the Thermal Effects during Hydrogen Charging in Packed Bed Storage Tank. Int. J. Heat Mass Transf. 2009, 52 (5), 14951503. https://doi.org/10.1016/j.ijheatmasstransfer.2008.06.045.

(44) Dubinin, M. M. Adsorption in Micropores. J. Colloid Interface Sci. 1967, 23 (4), 487499. https://doi.org/10.1016/0021-9797(67)90195-6.

(45) Dreisbach, F.; Sch, H. W. L.; Harting, P. Highest Pressure Adsorption Equilibria Data: Measurement with Magnetic Suspension Balance and Analysis with a New Adsorbent/Adsorbate-Volume. 15.

(46) Do, D. D.; Do, H. D. Adsorption of Supercritical fluids in Non-Porous and Porous Carbons: Analysis of Adsorbed Phase Volume and Density. 2003, 15.

(47) Czerny, A. M.; Bénard, P.; Chahine, R. Adsorption of Nitrogen on Granular Activated Carbon: Experiment and Modeling. Langmuir 2005, 21 (7), 2871-2875. https://doi.org/10.1021/la0479760.

(48) Levenberg, K. A Method for the Solution of Certain Non-Linear Problems in Least Squares. Q. Appl. Math. 1944, 2 (2), 164-168.

(49) Rouquerol, F.; Rouquerol, J.; Sing, K. S. W. 2 - Thermodynamics of Adsorption at the Gas/Solid Interface. In Adsorption by Powders and Porous Solids (Second Edition); Rouquerol, F., Rouquerol, J., Sing, K. S. W., Llewellyn, P., Maurin, G., Eds.; Academic Press: Oxford, 2014; pp 25-56. https://doi.org/10.1016/B978-0-08-0970356.00002-4.

(50) Jagiello, J.; Kenvin, J.; Celzard, A.; Fierro, V. Enhanced Resolution of Ultra Micropore Size Determination of Biochars and Activated Carbons by Dual Gas Analysis Using N2 and CO2 with 2D-NLDFT Adsorption Models. Carbon 2019, 144, 206-215. https://doi.org/10.1016/j.carbon.2018.12.028.

(51) Grau-Marin, D.; Silvestre-Albero, J.; Jardim, E. O.; Jagiello, J.; Betz, W. R.; Peña, L. E. Evaluation of the Textural Properties of Ultramicroporous Carbons Using Experimental and Theoretical Methods. Carbon 2020, 157, 495-505. https://doi.org/10.1016/j.carbon.2019.10.035.

(52) García-Díez, E.; Schaefer, S.; Sanchez-Sanchez, A.; Celzard, A.; Fierro, V.; MarotoValer, M. M.; García, S. Novel Porous Carbons Derived from Coal Tar Rejects: Assessment of the Role of Pore Texture in CO2 Capture under Realistic Postcombustion Operating Temperatures. ACS Appl. Mater. Interfaces 2019, 11 (40), 36789-36799. https://doi.org/10.1021/acsami.9b13247.

(53) de Lange, M. F.; Lin, L.-C.; Gascon, J.; Vlugt, T. J. H.; Kapteijn, F. Assessing the Surface Area of Porous Solids: Limitations, Probe Molecules, and Methods. Langmuir 2016, 32 (48), 12664-12675. https://doi.org/10.1021/acs.langmuir.6b03531.

(54) Peigney, A.; Laurent, Ch.; Flahaut, E.; Bacsa, R. R.; Rousset, A. Specific Surface Area of Carbon Nanotubes and Bundles of Carbon Nanotubes. Carbon 2001, 39 (4), 507514. https://doi.org/10.1016/S0008-6223(00)00155-X.

(55) Yu, X.; Tang, Z.; Sun, D.; Ouyang, L.; Zhu, M. Recent Advances and Remaining Challenges of Nanostructured Materials for Hydrogen Storage Applications. Prog. Mater. Sci. 2017, 88, 1-48. https://doi.org/10.1016/j.pmatsci.2017.03.001. 
(56) Müller, K. Technologies for the Storage of Hydrogen Part 1: Hydrogen Storage in the Narrower Sense. ChemBioEng Rev. 2019, 6 (3), 72-80. https://doi.org/10.1002/cben.201900009.

(57) Kadono, K.; Kajiura, H.; Shiraishi, M. Dense Hydrogen Adsorption on Carbon Subnanopores at 77 K. Appl. Phys. Lett. 2003, 83 (16), 3392-3394. https://doi.org/10.1063/1.1621073.

(58) Murata, K.; El-Merraoui, M.; Kaneko, K. A New Determination Method of Absolute Adsorption Isotherm of Supercritical Gases under High Pressure with a Special Relevance to Density-Functional Theory Study. J. Chem. Phys. 2001, 114 (9), 41964205. https://doi.org/10.1063/1.1344926.

(59) Yurduşen, A.; Yürüm, A.; Yürüm, Y. A Remarkable Increase in the Adsorbed H2 Amount: Influence of Pore Size Distribution on the $\mathrm{H} 2$ Adsorption Capacity of FeBTC. Int. J. Hydrog. Energy 2020, S0360319920308466. https://doi.org/10.1016/j.ijhydene.2020.02.202.

(60) Sdanghi, G.; Canevesi, R. L. S.; Celzard, A.; Thommes, M.; Fierro, V. Characterization of Carbon Materials for Hydrogen Storage and Compression. C - J. Carbon Res. 2020, 6 (3), 46. https://doi.org/10.3390/c6030046.

(61) Amankwab, K. A. G.; Schwakz, J. A. A Modified Approach for Estimating PseudoVapor Pressures in the Application of the Dubinin-Astakhov Equation. 7.

(62) Agarwal, R. K.; Schwarz, J. A. Analysis of High Pressure Adsorption of Gases on Activated Carbon by Potential Theory. Carbon 1988, 26 (6), 873-887. https://doi.org/10.1016/0008-6223(88)90111-X.

(63) Srinivasan, K.; Saha, B. B.; Ng, K. C.; Dutta, P.; Prasad, M. A Method for the Calculation of the Adsorbed Phase Volume and Pseudo-Saturation Pressure from Adsorption Isotherm Data on Activated Carbon. Phys Chem Chem Phys 2011, 13 (27), 12559-12570. https://doi.org/10.1039/C1CP20383E.

(64) Bhatia, S. K.; Myers, A. L. Optimum Conditions for Adsorptive Storage. Langmuir 2006, 22 (4), 1688-1700. https://doi.org/10.1021/la0523816.

(65) Myers, A. L.; Monson, P. A. Adsorption in Porous Materials at High Pressure: Theory and Experiment. Langmuir 2002, 18 (26), 10261-10273. https://doi.org/10.1021/la026399h.

(66) Palomino, G. T.; Cabello, C. P.; Areán, C. O. Enthalpy-Entropy Correlation for Hydrogen Adsorption on MOFs: Variable-Temperature FTIR Study of Hydrogen Adsorption on MIL-100(Cr) and MIL-101(Cr). Eur. J. Inorg. Chem. 2011, 2011 (11), 1703-1708. https://doi.org/10.1002/ejic.201001116.

(67) Garrone, E.; Bonelli, B.; Otero Areán, C. Enthalpy-Entropy Correlation for Hydrogen Adsorption on Zeolites. Chem. Phys. Lett. 2008, 456 (1), 68-70. https://doi.org/10.1016/j.cplett.2008.03.014.

(68) Che, S.; Pang, J.; Kalin, A. J.; Wang, C.; Ji, X.; Lee, J.; Cole, D.; Li, J.-L.; Tu, X.; Zhang, Q.; Zhou, H.-C.; Fang, L. Rigid Ladder-Type Porous Polymer Networks for Entropically Favorable Gas Adsorption. ACS Mater. Lett. 2020, 2 (1), 49-54. https://doi.org/10.1021/acsmaterialslett.9b00434.

(69) Pera-Titus, M. On an Isotherm Thermodynamically Consistent in Henry's Region for Describing Gas Adsorption in Microporous Materials. J. Colloid Interface Sci. 2010, 345 (2), 410-416. https://doi.org/10.1016/j.jcis.2010.01.027.

(70) Bickford, E. S.; Clemons, J.; Escallón, M. M.; Goins, K.; Lu, Z.; Miyawaki, J.; Pan, W.; Rangel-Méndez, R.; Senger, B.; Zhang, Y.; Radovic, L. R. On the Adsorption Affinity Coefficient of Carbon Dioxide in Microporous Carbons. Carbon 2004, 42 (8), 1867-1871. https://doi.org/10.1016/j.carbon.2004.02.026. 